\title{
Modern Production and Costing Methods as APPLIED TO LOCOMOTIVE ENGINEERING.
}

Paper read before the Institution by A. E. HOWELL, Member, Newcastle, on $3^{\text {rd } M a r c h, ~ 1922, ~ a t ~ M a n c h e s t e r, ~}$ 23rd March at London, and roth April at Leeds:

\section{Paper No. 123.}

The subject of production organisation and costs covers a very wide field, and the Author can only attempt to generalise on the main sections, leaving any further details to be discussed and amplified.

Production methods were entirely revolutionised by the lessons learnt during the war, and many ideas have had to be completely revised, particularly those regarding the status and payment of the employees.

The object of all production organisation is to facilitate manufacture by taking care to reduce the human element as far as possible to a negligible quantity. Man being fallible, good organisation and proper system of control will lessen his worry, increase his capacity, enable the firm 
to take work on for months ahead, ensure more or less security of tenure on the part of the workmen; and besides giving a man an interest in his job morally, will also give him one financially, i.e., payment by results.

The whole question of production revolves more or less round the question of accurate estimating, both labour and material, and the adherence as closely as possible to a time not greater than the maximum time allotted by the people responsible for controlling the manufacture. To give a general idea of what is meant, take an example; suppose several firms in this country are in competition with each other for an order, and are asked to quote for a certain article or machine; the procedure formerly adopted was, on receiving the inquiry and drawings, to get out the weights of the various material and the prices of that material at the current market value, either guess the machining and fitting times or take a comparison from a previous cost of the nearest thing they had, add to this on-cost-that is, the necessary percentage for heat, light, maintenance, salaries, etc., add a certain allowance to cover contingencies, and one for profit, and there was the price. This was more or less a rule-of-thumb method, and if fortunate enough to secure the order one did not know whether a profit or a loss would be made, or precisely how one stood. Obviously the fault with this method was that the labour estimate was more or less guess work, and since the Author claims it to be possible to fix a reasonable time for any machining operation, and also as it is becoming possible to fix a time for any hand operation, it thus becomes possible to ascertain with some degree of certainty what was previously an indefinite quantity-that is, the labour cost. By fixing this labour cost, and with the-co-operation of the employees and officials in setting themselves out in all cases to beat the allowance made for each particular operation, it is possible for a firm in negotiating for a contract to know precisely where they stand, and if they are short of work and desire to procure work to keep their workmen employed, they know absolutely how far they can go; but the Author reiterates that the firm must have the co-operation of their employees to do this. The benefit to the employees, of course, is that as it does not pay any works to keep its machinery idle, and the employer knowing. precisely where he stands will not need such a large contingency allowance as was required in. the past and is therefore in a better position to secure the order, which means work for the particular town in which the employer's works are situated and work for the particular employees who are 
incorporated. It should be pointed out that it is now accepted as a fallacy that increased and cheaper production per man or machine means a decreased amount of work available because by cheapening the cost of the article the field of its application is enlarged. As an instance of this, if one could buy a motor car for, say, $\mathcal{E}_{20}$, owing to increased and cheaper production there would be a greater number of motor cars used.

Now, coming down to actual production methods, briefly there are two kinds; the first is called mass. production for stock, as in the case of a motor-car, and secondly there is quantity production on orders as obtained as in the case of the works which the Author represents, i.e., the manufacturing of locomotives. The difference is this. In the first case the machines may be laid out and so arranged that one machine does one, two or more operations on a certain part and nothing else, and the machines are so arranged that the part passes from machine to machine, which is not a very difficult thing to organise. The second case of quantity production means that while the machines are so arranged that the work travels as much as possible along a straight path, it does not necessarily follow that the same machine is always doing the same job; in fact, in our works it would be impossible.

Carrying the fruits of our experience into present-day manufacturing, we are forced to the conclusion that in the past insufficient attention was paid to :-

(I) The ordering and obtaining delivery of material (both rough and finished).

(2) The flow of material through the shops.

(3) The sequence and planning of machining and fitting operations.

(4) Rate fixing and general organisation of manufacture.

In fact, far too much was left to the individual, and generally speaking, there was no department or official apart from the works manager or chief engineer whose concern was the linking up of the various shops or departments and their functions.

The above statement refers to the majority of engineering shops in this country, very few engineering shops having at the outbreak of war either a progress, production or planning department, as it is now understood in the best organised and equipped shops.

The manufacturing side of engineering would appear 
(apart from the question of labour) to resolve itself into three main problems, which are as follows :-

(I) Obtaining rough material (inside or outside).

(2) Obtaining finished material (for assembly or erection).

(3) Erection and painting.

Under the first two headings are the main problems, for by solving these two the last is not so difficult.

It has been found possible to fix up, obtain and maintain deliveries coming under the first two headings by fixing a period from the date of receipt of order to the final delivery date, subdividing this period into particular numbers of days and allotting a certain time to each and every shop to complete its allotted task, such time meshing into the general scheme of things, fixed on a consistent basis and controlled by methods reducing the human element to a negligible or minimum quantity.

Although every shop is a law unto itself, the Author hopes that the following main lines laid down, the majority of whose component parts are common, will help along and tend to consolidate thought upon scientific manufacturing, which will ultimately result in a more or less standard method of procedure in manufacturing engineering.

The following is an outline of a general scheme of organisation which can be modified and adapted to suit most manufacturing shops.

The scheme assumes a staff and organisation as chart (Fig. I) from which it will be seen that a planning and production office is included. The latter office or department being a fairly recent development will be dealt with in fuller detail, whilst the other departments will only be touched upon where their organisation affects the general scheme, and the Author offers no apologies for going over familiar ground in view of the fact that what is familiar to one is strange to another, and the purport of this Paper is to throw possibly some new light on familiar ground.

The general organisation is of the military type known as Line Organisation (see Fig. I), which gives definite responsibility, and with a good personnel comprises, in the opinion of the best authorities, the most effective type.

Functional or staff organisation, under which an employee can receive orders from several superiors all of equal authority, tends to subvert discipline and leads to many costly mistakes. 
Unit assembly, or the assembly of detail parts into complete units prior to the units being assembled into a machine, has been adopted instead of general assembly (where each individual part is assembled into the finished machine) for the reasons enumerated below. By keeping the number of parts to a minimum, handling is saved, confusion avoided, time is gained and shops arranged better. Also, by shortening the path a part has to travel along, one can keep track of its movements better.

The works in general should be arranged, as far as possible, so that material enters one end and flows through in a straight line, having the various operations performed on it as it goes along and never returning along a path it once has traversed. Thus the stores would be situated at one end, followed by the foundry, smithy, forge, etc., after which the various machine shops in their order through to the erecting or assembling shops and on through the painti shop to final store, and so out to customer.

The interior of the various shops should be so arranged. that each bay or section deals with the necessary number of items comprising one unit, so that the parts comprising. one unit are machined and assembled into that unit before passing on to the final assembly, any necessary partscoming from stock or outside being joined up to their particular unit in its section before passing out.

General Identification of Orders and Parts.-There are two ways of identifying parts, either by taking each unit assembly and allotting a number to each individual part, that is to say, allotting to a unit assembly numbers from: 1 to 400 , and giving a sectional number to each part, such as Cylinders No. I, Cylinder Covers No. 2, Steam Chest Covers No. 3, etc., or by using the method which we have in operation in our own works, which is as follows :-Each individual order is allotted a letter, say " $\mathrm{B}$," and a number in rotation corresponding to the date of receipt of the order. The machine to be manufactured is divided into its unit assemblies and a letter allotted to each complete unit assembly, which is further subdivided into its parts by a number placed after its unit letter (see Fig. 2).

Thus $\mathrm{B}_{1} / \mathrm{C}_{3}$ would be order $\mathrm{B}_{1}$, group $\mathrm{C}$, section 3 , and" should any item require to be specifically referred to, the item number can be placed after the group and section number so that $\mathrm{BI}_{\mathrm{I}} / \mathrm{C}_{3} / \mathrm{I}_{4} \mathrm{O}$ would be item $\mathrm{I} 4 \mathrm{O}$ on the order group and section previously referred to.

The method is also adopted in the line up sheet (where any operation is referred to by quoting the group, section; 
page No. and line, so that $\mathrm{BI}_{\mathrm{I}} / \mathrm{C}_{3} / 30 /$ Io would mean order $\mathrm{BI}$, group $\mathrm{C}$, section 3 , page 30 , line $\mathrm{IO}$ ).

The works, as before remarked, being so arranged that convenient divisions deal with each group of unit assemblies, anyone knowing the group letter of any particular material can instantly refer to its correct shop section, and consequently its proper place in the general scheme of things, without having to look up drawings or consult the foremen or superintendent.

\section{The Drawing Office.}

Upon an order being received by the chief draughtsman it is handed over to the leading draughtsman of that particular section, who, after going through the specification, draws up the list of drawings required and allots the necessary drawing and sketch numbers.

After having obtained the time limit set by the production department when the drawings must be ready in sequence, he sets his -men on to the various key or arrangement drawings, having a watchful eye upon the requisitioning of all parts requiring the longest time to procure or manufacture, such as special forgings, steel castings, all in relation to the order of building. A schedule (Fig. 4) giving particulars of all quantities and sizes of every individual part is put on each drawing as well as a separate copy filed in its appropriate section, the whole comprising a complete şchedule of every part on the order.

Fig. 3 is an illustration of the order as sent to the drawing office, and, as will be seen, after the detailed order come spaces for the drawing name, number, when drawn, when traced and checked, when list of material is issued to shop, and the various shops into which drawings have to be sent and the date inserted upon which the blue prints were delivered to shops.

As a drawing is made the space is ticked off and the same occurs when it is traced and checked.

The issue of the schedules and prints to the shops can be seen by the inserted dates, and as the requisitions to purchasing department for material to be ordered outside are sent out the master schedule is stamped with a small dating stamp. Copies of all schedules issued (Fig. 4) are sent to the stores, etc., and these are used in the stores to record the movements of the material, a blank space printed white being left at the right hand side or else a loose leaf 
inserted underneath each list in the file for filling in dates of receipt and quantities of the items sent to the stores.

Requisitions for material to come from outside are marked by the production department with the required delivery date and shop to which to be delivered, before being sent to the purchasing agent to buy the necessary material.

All questions relating to drop stampings or forgings, pressing dies and other methods of manufacture, are referred by the drawing office to the production department, who settle all such methods of manufacture.

\section{Production Engineer and Department.}

The production engineer can be likened to an executive works manager, the actual works manager being concerned more with the administration.

The functions of the production engineer and his department are :-

To settle the precedence of detail orders and their iespective delivery dates.

To procure the material in a given sequence, transmit it to the shops together with all necessary drawings, jigs, tools, gauges and other special fixtures (having previously overcome all apparent difficulties in the manufacturing), progress the job and bring the various components and unit assemblies to the erecting shops each in its predetermined time, dealing with all delay, defective material, faulty design, breakages, alterations, etc.

In fact, the object of the production department is to take as much responsibility as possible away from the shop rexecutive so that labour control, demonstrating that work can be done in the estimated times and keeping the machines fully occupied on production will be the main duties of the foreman. The production department delivers to him the material, tells him the machine on which the job is to be done, the method to employ, supplies jigs, tools, gauges, etc., and calculates times for execution and estimate of price which should be paid.

It naturally follows that the production engineer must be a good practical as well as theoretical man, have administrative qualifications and a generous share of tact, the latter being a sine, qua non, as his duties bring him in conflict with practically everybody on the ground, having to control 
both material, method and personnel with a view to the most effective use of each and all.

Under his control and comprising his department are the planning, estimating, rate fixing, progress, jig and tool drawing office, plan stores, speed and feedmen, etc., which are more or less dealt with separately.

The production engineer or his assistants are always on hand to give immediate decisions on any points arising, and also keep a watchful eye on shop methods, speeds and feeds, operation of jigs and machines, with a view to easier and quicker manufacture. One of his staff is always held ready to send to the shop to supervise the execution of the first detail of a lot where a price is challenged.

\section{CONTROL.}

\section{Dating of Parts and Order of Building.}

Having received the order, an order of building or assembly is first of all determined for the locomotive or machine to be built (Fig. 5), the various parts being divided into groups of component assemblies or similar convenient divisions.

A time limit in days is fixed for the final delivery and a proportionate number of days allowed for each shop, the longest time being allowed for procuring the material and getting the forgings, castings, stampings, etc., into the machine shops (see example Fig. 6).

A convenient datum line having been fixed at the main basic part, say the frames, the individual unit assemblies are dated so many days before or so many days behind the datum according to the amount of machining or other work to be done on the components. This dating gives a definite date for the material to arrive at the store, also machine, erecting and other shops right up to date of final delivery.

The drawing office has so many days to get out the drawings, i.e., delivery of blue prints in the order of building must commence on a certain date and finish on another date.

Pattern shop, forge, smithy, foundry and machine shops are on the same lines, and in the case of material bought outside the drawing office requisition is sent to the production department, where the date the material is required to be delivered is fixed.

The consistent fixing of dates is done by means of the dating wheel (see Figs. 7 and 8), which comprises two discs, 
one of which has its circumference divided into $3^{6} 5$ days, also marked in the months of the year, while the other carries the relative order of building, marks being placed at intervals showing the definite number of days from the basis. or datum line required to complete each detail indicated, from which the date for each process can be read off at a glance. In effect it is a circular slide rule.

To fix a date (outside, machine, or other source) the datum line is set opposite the final delivery date, when the required delivery date will be found opposite the name of the part required.

It will, of course, be understood that parts are in the shops being machined in many cases before the whole of the drawings are completed, the drawings and requisitions. having been made and issued as far as possible in the order of building.

\section{Routing or Planning.}

The drawings are supplied to the engineer planner in. the order of building as far as possible. He takes each item separately, and having a complete lay-out of the shops and a card index of all machines, giving capacities, feeds, speeds, etc. (Fig. Io), he can plan a job to suit any particular machine or group of machines in the section, having also in mind the path the item has to travel. At the same time he notes on a form for the job any special jigs, tools, fixtures, and gives the number of articles to be machined at one setting, i.e., batch.

The jig and tool list is transmitted to the jig and tool. drawing office attached to the production department for the purpose of designing, the planning being made on a standard form in the correct sequence necessary to get each item in its correct order (Fig. I2). As each drawing is planned it is ticked off on the drawing list supplied by the drawing office (Fig. II). The planning is written in pencil on the line-up form, or schedule of operations, and is sent to the line-up typist, who types it in triplicate.

It is necessary for the planner to be a good all-round practical machineman, able to visualise all the necessary operations in their correct sequence to machine a part; any technical questions arising are generally discussed with another member of the staff and, if not satisfactorily arranged, are taken up with the chief or his assistant.

In cases of doubt as to the best sequence to adopt, which often arises when starting up this system, the planner- 
goes into the job and the methods with the foreman concerned and arranges the matter before issuing the planning to the estimator and line-up typist, the court of appeal being the production engineer, whose decision is final.

\section{Line-up.}

The line-up sheet is to the machine, fitting and other shops what the material schedule is to the drawing office and stores, being a record of where the material is coming from and the machining and fitting operations required upon each individual item except in the case of bolts, nuts and other standard parts which come from stock. A copy of the line-up is retained in the production department; one copy goes to the department concerned and the third copy goes to the works accountant.

A line-up can be made in either of two ways. The first way is to have in rotation each and every operation on any one item, irrespective of the number of shops it may go into (Fig. I2), and the second way is to group together all the machining done in the same shop and transfer the item from one shop sectional line-up to another.

The first method is more suitable for a small shop or mass production, while the second method is more convenient for a large works divided into a number of shops, as the line-up sheet can be issued to the foreman over the shop and gives him information as to where his material is. coming from and where he has to send it to when he has performed his particular machining or fitting operations. upon it.

For every operation a job ticket is issued (Fig. I3), giving piecework prices and other details.

\section{Estimating Machine and Hand Labour Times.}

The necessity for correctly estimating each and every machining operation may not be apparent at first sight, but in any machine shop, especially one worked in the past by more or less rule-of-thumb methods, estimating properly done will result in a great saving of machine time, conduce to the correct balancing of the machines and labour avail-able, and is necessary to the fixing of equitable piecework prices. In a shop manufacturing different sizes of similar machines, correct detailed estimates are necessary for about three or four different sizes of average standard manufacture, after which the other sizes can be deducted by inspections of the ones already estimated and the initial estimating. 
staff reduced to numbers needed for dealing only with fresh designs. Separate charts can be devised for small details. An example (Fig. 27) is given for hexagon-headed bolts.

For estimating the machining time on any part, one of two methods can be used, either by calculation or by reading directly from a chart. To accomplish this we must first of all originate a fair feed and speed table.

We have adopted as a basis only a " mean cutting speed "for the following reasons:-

With a miscellaneous collection of machinery, not all of modern types and yet some of the latest patterns, it is possible to have two similar machines on the same class of work, one of which has unlimited belt or motor power and able to take off a heavy cut at a high speed, whilst the other, although quite a good machine, has not the reserve of power; again, owing to the difference in design a cut which will be possible on the one machine will set up a vibration and chatter on the other. After considering the matter from these and other view points, it appeared better to take a mean or average speed and inform the machine shop that it is expected they will at least equal the times set.

In arriving at the foregoing conclusions, the company were quite alive to the provision of slide rules for each individual or class of machine proposed by Mr. Carl Barth in his paper on "Slide Rules for the Machine Shop as part of the Taylor System of Management." Whilst in theory this slide rule system is ideal, the opinion is that manufacturing has not yet been reduced to such fine limits as to make desirable the use of a slide rule for each and every machine, except where identical machines exist in not less than groups of five. Even then it is a difficult matter to keep all machines in time and tune to accord with their slide rule rating, especially if they are belt-driven.

The following (Fig. I4) is a table of mean feeds and speeds, also the necessary formula for calculation, and the charts Figs. I 5 to 23 , for direct reading, together with example Fig. 24, worked out for the benefit of anyone desiring to set up such a system.

The planning being received by the estimator, he estimates the machining and other times on the standard form (Fig. 24) as shown, which is afterwards handed to the rate fixer for the purpose of fixing a rate to be put on to the line-up sheet.

\section{Formulæ.}

By the use of the following formulæ and tables esti- 
mates can be got out for practically any machining operation, or a quicker method, which is equally as good, is to read directly from the charts giving the time for performing that particular part operation. These charts are specially adapted for the use of technical clerks, who, under the superintendence of an engineer, can manage the job quite satisfactorily.

$$
\text { Drilling }=\frac{\begin{array}{c}
\text { Depth } " \times \text { No. of holes } \times \text { feeds (i.e., } \\
\text { No. of rers. per inch) } \text { per inch }
\end{array}}{\text { R.P.M. (revs. per min.) }}
$$

For difference in depth due to drill point add $\frac{1}{4}$ of drill dia. If $\frac{1}{2}$ of drill dia. be added this gives allowance for clearing through hole.

$$
\begin{gathered}
\text { FACING }=\frac{\text { Breadth } " \times \text { No. of cuts } \times \text { feed }}{\text { R.P.M. }}=\text { minutes. } \\
\text { Cutting speed }=\frac{\mathrm{D}^{\prime}-d^{\prime} \times \pi \times \text { R.P.M. }}{2}=\begin{array}{c}
\text { F.P.M. } \\
\text { (ft. per min.) }
\end{array} \\
\text { R.P.M. }=\frac{\text { Cutting speed F.P.M. } \times 2}{\left(\mathrm{D}^{\prime}-d^{\prime}\right) \pi} \\
\text { MILLING }=\frac{\text { Length" } \times \text { No. of cuts }}{\text { Feed " per min. }}=\text { minutes. }
\end{gathered}
$$

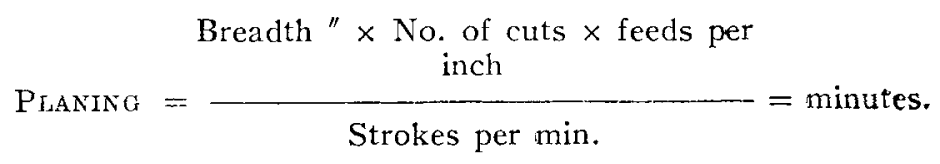

$$
\text { Strokes per min. }=\frac{\text { Cutting speed F.P.M. }}{\text { Length of stroke in ft. }}
$$

Allow more on forgings than on castings, and in no case less than one rough cut and one finish cut, generally two 
428 JOTRNAL OF THE INST. OF LOCO. ENGINEERS.

rough and one finish. Finishing cut is at lower speed than roughing cut. In all cases allow for return to cutting stroke as follows:-

$$
\begin{gathered}
\text { Return } 3 \text { to I add } \frac{1}{3} \text { cutting time. } \\
,, \quad 2, " \text { I }, \frac{1}{2} \text { ", " } \\
, " \quad \text { I }, " \text { r double " " } \\
\text { SHAPING = Same as planing. }
\end{gathered}
$$

SLotting $=\frac{\text { Breadth " } \times \text { No. of cuts } \times \text { feeds per inch }}{\text { Strokes per min. }}=$ mins.

$$
\text { Strokes per min. }=\frac{\text { Cutting speed "per min. }}{\text { Depth of stroke" }}
$$

Depth of stroke $=$ Length of stroke or height of job.

$$
\begin{gathered}
\text { TuRnING }=\frac{\text { Length } " \times \text { No. of cuts } \times \text { feeds per inch }}{\text { R.P.M. }}=\text { minutes. } \\
\text { R.P.M. }=\frac{\text { Cutting speed F.P.M. }}{d^{\prime \prime} \times \pi / 12}
\end{gathered}
$$

BORING $=$ Same as turning.

KNIFING = Same as boring only take depth instead of length

Countersinking $=$ Take mean dia and same formulæ as drilling.

Additional times are allowed for setting, gauging, changing tools, cleaning table, machine allowance (stopping and starting), taking out, and to full total add contingency allowance. Max., min. and average allowances are given, also useful tables (Figs. I5 to 23). 


\section{Rate Fixing.}

The rate fixer is provided with a card index (Figs. 25 and 26) from which he can see what prices have already been issued for similar jobs, though possibly of different size; he selects the nearest one to the particular case he is considering, and looks up the detail card (Fig. 26), which gives a sketch of the parts, and compares it with the one he wants.

If the job has not been priced before, he takes out the estimated time, and therefrom, with a table of decimal pence per minute for definite rates per hour, he calculates the exact amount, then adds the percentage according to whether it is straight piecework, premium bonus, etc., and issues the proposed price to the foreman or superintendent concerned, who then bargains with the workmen, and upon the foreman notifying the acceptance of the price it is entered upon the line-up and the job ticket.

The rate fixer never deals directly with the workman, all dealings being made through the man's superior in the shop. Thus the rates are more impartial than where any personal element is allowed to creep in. All rates are calculated on the basis rate of wages, so that any awards given afterwards can be added as a percentage without altering the prices and causing confusion.

In cases where there are a large number of small parts, such as studs, bolts, nuts, etc., or where a large number of holes have to be drilled, a standard chart can generally be drawn up by the following method:-

(I) Plot a curve whose vertical ordinates represent the size of article, and horizontal ordinates the time by estimate. (In cases where machines are not brought into such efficient condition as to be capable of giving the basis speed of output, the above must be checked from an actual trial and the machine brought up to standard efficiency; even then the output will not probably exactly coincide with the estimate under No. 1.)

(2) Plot the curves for the actual times after the machines have been brought into line. A mean curve lying between Nos. I and 2 is made the standard curve, and the prices are read off below the corresponding times.

Examples are given (Figs. 27 to 29 ) for :-

(I) Hexagon head bolts twrned from bar, with corrections for various shapes of heads and ends.

(2) Drilled holes through plates.

(3) Setting times for plates, etc. 
In fact all automatic or semi-automatic machine work can be charted and prices shown per roo.

A fixed price, which once having been accepted is guaranteed against cutting, was adopted, because most of the trouble and disputes over systems of payment by results arise owing to the inability of the workman to readily calculate his earnings, and in these days of rates plus a percentage for this and a percentage for that, it takes a workman of a mathematical turn of mind to be able to calculate his day rate, let alone his earnings under a bonus system. Any job not readily calculated is considered by the rate fixer and foreman together and, after making any necessary alterations to the feeds and speeds, a rate is fixed.

In addition to the before-mentioned charts for small details, endeavours have been made to obtain standard times for the many items on a locomotive, and although the investigations are still proceeding, appended are some of the early deductions. It must be borne in mind that these are approximate only, and are given in the hope that other investigators will probably criticise, and give the benefit of their experience. It may be said that instead of giving an average a maximum and minimum could be given, but examples are deduced from such a diversity of types that a sketch would be necessary to explain the variations, and this is hardly within the scope of this Paper.

\section{Approximate Standard Times.}

Frame Plates.-Drilling and slotting varies in proportion to weight or cubic dimension of rough plates (in batch).

Average for slotting... $\quad \ldots \quad 5 \frac{1}{2}$ hours per ton.

$\begin{array}{lllllllll}\text { Drilling } & \ldots & \ldots & \ldots & 9 & , \text {, } & \end{array}$

Assembling $\quad \ldots \quad \ldots \quad \ldots \quad 40 \quad, \quad$, $40 \quad$,

Cylinders.-Boring, facing, planing and drilling. cylinders (combined operations) varies in proportion to cylinder diameter $\times$ stroke, and averages six minutes per. inch of $\mathrm{D} \times \mathrm{S}$.

Cylinder Covers.--Turning, boring, facing, recessing, and drilling varies the same as cylinders, and averages $2 \frac{1}{2}$. minutes per inch $\mathrm{D} \times \mathrm{S}$ for both ends.

Piston Rods.--Turning, screwing, and slotting (exclusive of grinding) varies in proportion to cylinder diameter $\times$ stroke, and averages 2.2 minutes per inch.

Pistons.-Turning, boring, facing, and recessing varies. 
in proportion to diameter only of cylinder, and averages $8 \frac{1}{2}$ minutes per inch of diameter.

Crosshead and Slippers, Connecting Rods and Straps.Milling, drilling, slotting, etc., varies in proportion to diameter of cylinder, and according to design.

Piston I'alves.-Machining all parts and fitting complete varies in proportion to diameter of cylinder, and averages $10 \frac{1}{2}$ hours per inch of cylinder diameter.

Axleboxes. With keeps and bushes completely machined (exclusive of small fittings), varies in proportion to diameter of journal, and according to design. Average times are :-

Wrought iron ... $7 \frac{1}{4}$ hours per inch of diameter.

Cast steel $\quad \ldots \quad 61$, , , ,

Cast iron $\quad \ldots 66 \frac{1}{4} \quad, \quad,$,

Gunmetal … $2 \frac{1}{2}$," ,", ,"

Average fitting $2 \frac{1}{2}$ hours per inch of diameter.

Wheel Tyres.-(I) Turning, boring, recessing and forming spigot for rolling over ring, varies in proportion to diameter on wheel tread. Average $5 \frac{1}{2}$ hours per foot of wheel diameter on tread. (2) Turning, boring and facing only varies same as above, and averages $2 \frac{1}{4}$ hours per foot of wheel diameter on tread.

Wheel Centres, Engine.-Turning, boring and facing exclusive of crank pin holes varies in proportion to wheel diameter, and averages 3 hours per foot of diameter of tread of tyre.

Wheel Centres, Tender.-Equals $2 \frac{1}{4}$ hours per foot of diameter of tread of tyre.

\section{General and Shop Material chart.}

The progress of the work done on each item is recorded on job ticket (Fig. 13), which is brought into the production. office and entered up.

The general situation with regard to material received, delivered to shops, machining performed, and material en route to erection, is controlled by means of the control chart, which is a large chart about $6 \mathrm{ft}$. high and $12 \mathrm{ft}$. long, fixed on the wall of the production department, and represents progress over six months of the year.

The idea of this chart is that the actual position of work in the shops may be instantaneously compared with the progress which should have been made according to the 
predetermined programme, in order that progress shall proceed without delay.

The chart is like a large sheet of squared paper (Fig. 9), whose horizontal ordinates represent unit assemblies in alphabetical order, and whose vertical ordinates represent months divided into days.

The chart itself, which is fastened direct to the wall, is a fixture, and is divided into horizontal lines; on the left-hand edge are entered in a vertical column in sectional alphabetical order the various items to be controlled. The rest of this fixed chart is ruled with vertical lines, each of which is headed with consecutive figures, giving the dates reckoned from the left. Each square thus formed by the intersection of the horizontal and vertical lines is provided with a hook or push button on which the indicating disc can be fixed. Green discs are prepared on face of which are noted in Indian ink the single sets or number of sets of each item whose delivery in the erecting shop it is desired to control. The record is started by using the dating wheel referred to by which, having the date of delivery given, the date is read off at which each item shown in the left-hand column should reach the erecting shop. The member of the staff in charge of the charts, using the dating wheel, works out the date for each unit assembly on the chart left-hand column, and fixes the green disc on the correct hook or press button, this showing once for all the delivery required for that item or set.

Now to read off the present position of the work a travelling cursor is used, which consists of a vertical blade like a large $T$-square blade, which travels across the face of the fixed chart. This blade is provided with three vertical rows of hooks; the right row of hooks is used to show the number of complete sets of material delivered to the erecting shop; for this purpose a set of yellow discs is used on which are noted in Indian ink the number of sets delivered to the erecting shop up to date, entered up daily from the copy of the shop delivery note to the erecting shop.

If the number of sets shown on the yellow disc is the full number entered on the green disc in the same horizontal row of the fixed chart, the man in charge unhooks the green disc; thus the number of green discs shows at a glance all material not delivered to the erecting shop.

The centre row of hooks is used to show the number of complete sets of material delivered to the machine and fitting shops; for this purpose a set of red discs is used, on which are noted in Indian ink the number of sets delivered to the 
machine and fitting shops, entered up daily from a copy of the stores delivery notes.

The left row of hooks is used to show the number of complete sets of materials received; for this purpose a set of blue discs is used, which are noted in the like manner to the former, the particulars being obtained from the stores department.

Each separate order has its own series of coloured discs, all of a distinctive shape, i.e., round, square, diamond, oval, etc.

Another sliding cursor with the corresponding names of the unit assemblies opposite their respective lines is made so that it can be brought to any desired day and a line instantly noted.

Thus it will be seen that the chart gives immediately the position of any unit assembly on any order as regards material in stores, material delivered to machine shop, material delivered to erecting shop, and what its position should have been on that date. Any unit which appears behindhand on the chart may have the details instantly referred to, the particular item causing the delay ascertained, and a chaser sent after it, or some steps taken to enable the unit to come up to time.

The chart is changed daily, and up-to-date information regarding the position of any item in the works is available for reference at the weekly meeting of representatives of each main department, i.e., supply, stores, forge, foundry, machine and erecting shops, when all hold-ups are discussed, the production department being the clearing house for all shop troubles except labour.

The material section of the production office keeps a sheet which sub-divides the unit assembly into its component items, and against each item daily is given the number of that particular item or part received to date, and as necessarily the lowest number of any one item constitutes the maximum number of sets which is entered on the daily column and sent to the chart man to enable the chart to be adjusted.

In conjunction with the dating wheel, green discs are placed on the chart at various stages, indicating the programme laid down so that actual progress can be seen on the chart alongside the programme progress, the overlap and position of the various orders being seen at a glance, and when the sales department is inquiring for probable delivery dates for new orders or inquiries, the job can be charted up 
and its position with regard to existing orders noted and approximate delivery dates given.

The green discs representing the day certain sets of finished unit assemblies should have arrived at the crecting shop have to be set on the chart in the order of building. For this purpose a setting cursor is used (see Fig. 9), so that discs can be rapidly put up, and there can be no doubt about their position being accurate as it can readily be checked.

\section{Machine Balance and Nomination.}

After the estimated time for each machining and hand operation has been arrived at, for the purpose of quantity production, it will be necessary to balance both the machine and the hand labour loads.

This is done by taking out the estimated times which will be required by each different class of machine to machine each different item, and multiplying by the number of items to be machined. The answer is a total of machine hours for that class of machine. Dividing by the number of these machines available will give a certain figure. The same being done for each class of machine, the resulting ultimate figure or ratio should be approximately the same in each case; if so, the machines are balanced. If they differ by any appreciable amount, arrangements must be made to relieve some of the peak load so that all machines can be kept up to their maximum output.

In a like manner the hand labour hours can be got out for the hand operations, and arrangements can be made to either increase or decrease the number of men employed to balance the hand labour load.

By balancing each section separately (Figs. 30 and $3 \mathrm{I}$ ) in this way and taking the out-of-balance load of that section and comparing it with the corresponding out-of-balance loads of other sections, it should practically cancel out if the shops be properly balanced. If it does not do so, more machines or men are necessary or different methods of machining and fitting should be adopted to overcome this difficulty.

Again, by combining all the orders on hand over a given period, the output of the shops can be forecast with some degree of accuracy (Figs. $3^{2}$ and 33 ).

We can go further than this, and by allotting each job to the most suitable machine in its section when planning (a process called nomination) can relieve the shop foreman of a great deal of worry and anxiety. 
At the same time, if a card index be kept, a card for each machine on which its nominated work and estimated time is given, the machine can have its work fixed for months ahead.

Should a breakdown occur to one machine, another can be nominated to relieve it, and other corrections can be made for the increase or decrease of actual to estimated time.

As all estimates are made on an average or mean cutting speed, generally speaking the shops take less than the estimated times, especially where piecework is in vogue.

A large plan of the machine shops showing each machine in position can be kept, and when a machine is reported out of order an indication placed over it so that the number of breakdowns and corresponding delays can easily be seen and arrangements made to transfer the work until the breakdown is repaired and the machine reported ready for running again.

\section{Stores Organisation.}

Material required is authorised by drawing office, and controller of purchasing and stores department arranges supply.

Copies of all orders are in the hands of the stores department so that deliveries against such orders may be checked and records made for the passing of invoices. The preliminary operation in regard to receipt of material is the receipt of an advice, but the receiving system must be such that goods are not held up in the stores if such advice is not to hand.

The disposal of material entering the stores may be effected by having the Order No. quoted by the senders either on the containing package or in some other visible method.

No matter what is received for a specific job, i.e., one may have a contract for roo machines, the material for which may come in in such quantities as to make it impossible for the shops to carry. All material is a debit to the stores department, and only a credit to the latter and a debit to "work in progress" when requisitioned by works department from stores department.

The point in this is that material entering into progress will synchronise with wages period, and that the charge against an order will only be made at the time the material is called for. Further, it is only by this means the head administration can be kept informed on many points of importance which need not, I think, be enumerated, here. 


\section{Costing System.}

In manufacturing engineering, too great a stress cannot be laid upon the obtaining of accurate detail costs as soon as possible, bearing in mind that cost history is not of much use, and cost news is what is required, meaning that a system which cannot give an individual cost per item in a very short time is in a very delicate state, for being unable to obtain the cost of any individual part, and unable to state which jobs are costing too much, and being unable to put one's finger on the item concerned before it has gone too far, is a very serious matter.

Output may remain constant and wages double; in fact, anything may happen and the management be unaware of the actual seat of the trouble until the damage is done.

The old system of costing up a job after it was finished is not good enough, and although weekly statements of wages and material expenditure on each order should be furnished to the management, the actual time taken on the first article of a lot should be furnished to the production department at once, the main object being to get detailed cost information immediately the jobs are in operation so that any excess cost may be at once investigated instead of waiting until the whole job or parts are machined or fitted. In this way we have found operations costing as much as 300 per cent. more than the estimated time to machine and fit, and investigation has shown the problem of reduction to be comparatively simple, the excess being perhaps due, e.g., to too much machining allowance on castings, bad forgings, inadequate equipment, extra finishing on jobs, as well as incorrect charges.

By getting the information through almost immediately, corrections can be made and the cost reduced before many of the particular details have been finished. The way we do this in our own works is by means of sorting and tabulating machines, of which, without attempting a technical description, it is enough to say the fundamental idea is the recording of certain selected facts by punching out figures on cards, which figures represent codes, shops, machine numbers, orders, sub-section and details, operations, number done, hours taken and the wages, day work or piecework, and the sorting and tabulating of these cards by electrical machinery. These perforated cards are sorted by the electrical sorting machine into the particular shop, group, or machines required, and the machine sorts at the rate of 15,000 cards per hour, and by successive sorting, 
figures can be obtained not only for any single group, but for any combination of groups.

The principle of electrical tabulating is the completion of electrical circuits through perforations in cards, the position of the holes determining the result registered by the tabulator. The cards having been sorted into the required groups, the cost of any section, any particular operation, on any particular series of machines, or any other kind of information which one wishes to compute, may be added simultaneously on the electrical tabulating machine at the rate of 9,000 cards per hour, which on a machine equipped with five counters means 45,000 items per hour added. The totals shown on the counters are written down and the operation is complete. Obviously it is a fact that statistics can be compiled in minutes by this method which would otherwise take hours, and they are absolutely correct, the great advantage being that information is available to provide what is wanted when it is wanted, and when the knowledge is of value, without having to wait so long for the information that when one gets it it is too late to take action. By putting in cards representing the estimated time, Figs. 34 and 35 , and tabulating and comparing them with cards representing the actual time, the efficiency of a particular section or a particular group of machines can be immediately found, and variations can be watched from week to week, and thus the balance of shops can be maintained.

Fig. 34 shows a machine balance card, and Fig. 35 one of the hand balance cards.

Charts' should be kept in graph form showing the percentage of productive to unproductive labour; also lost time due to"sickness and other causes, so that any increase in unproductive labour will be readily seen and steps taken to correct it.

For the purpose of having a further check on the shop, a weekly report giving the percentage of piecework hours to the total hours worked should be got out for each particular shop, so that any drop in the percentage of piecework may be instantly noted; further to this a list should be got out, also weekly, called " The Excess Sheet," giving the names, the shops and the jobs, together with the piece price and the amount it has cost. A further list should be prepared of any men failing to make time and third, so that the matter can be investigated, and if the fault is due to the inadequate equipment or a machine is not being. properly maintained, it will be found out and steps taken to have the matter put right by the persons concerned. 


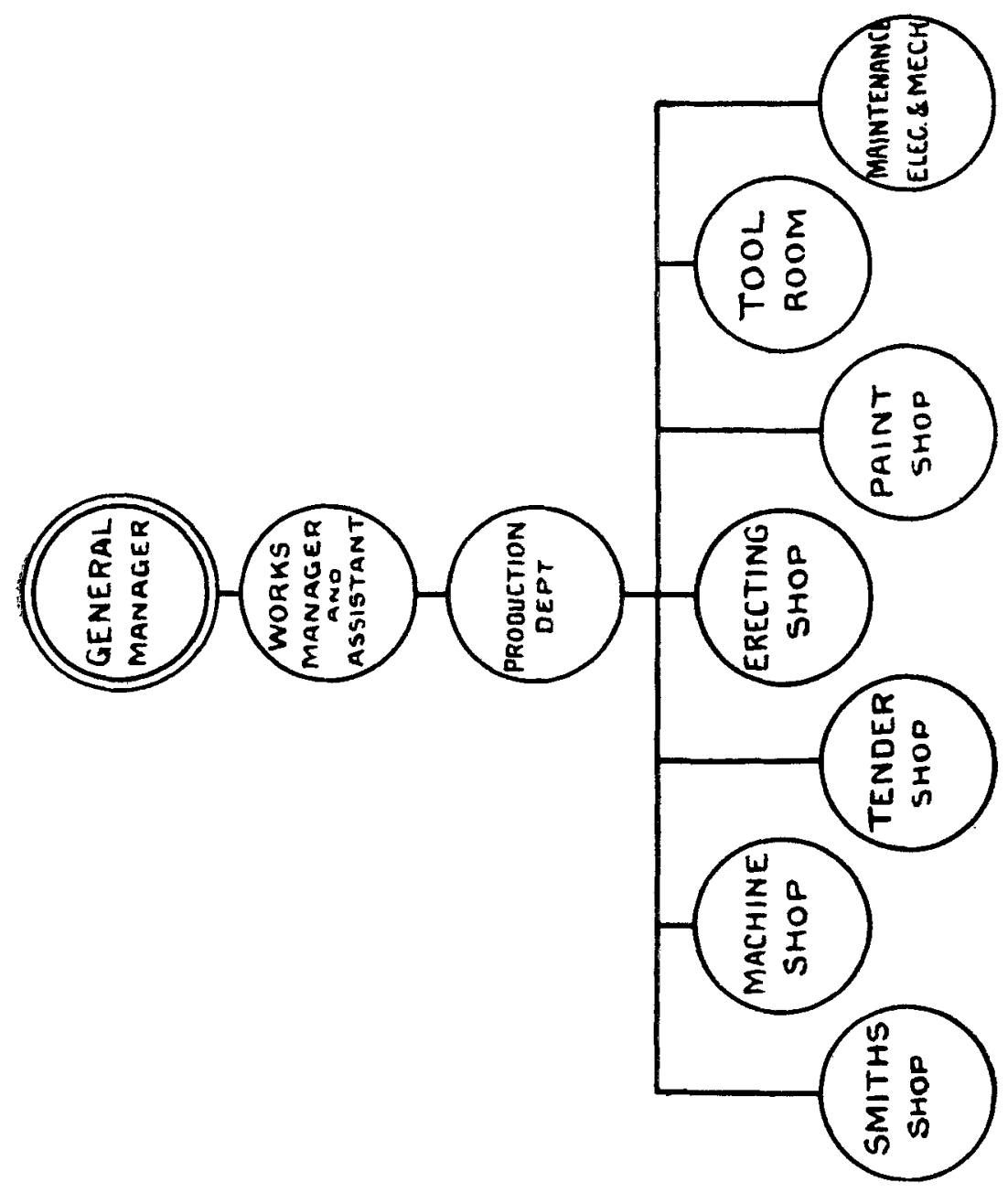

Fig. 1. 


\title{
LOCOMOTIVES.
}

\section{WORKING SECTIONS AND NUMBERS. TENDER BOGIES.}

\author{
Section L. \\ Working \\ No. Part. \\ I. Erection. \\ 2. Frame complete with cross-stays. \\ 3. Hornblocks and keeps. \\ 4. Axleboxes. \\ 5. Springs. \\ 6. Spring rigging. \\ 7. Brake gear. \\ 8. Centre and side bearings.
}

FIG. 2. 
$44^{\circ}$ JOURNAL OF THE INST. OF LOCO. ENGINEERS.

D.O. ORDERS. No.

\begin{tabular}{ll} 
For & Date Ordered \\
\hline & Date ReQUired \\
\hline
\end{tabular}

DESCRIPTION :-

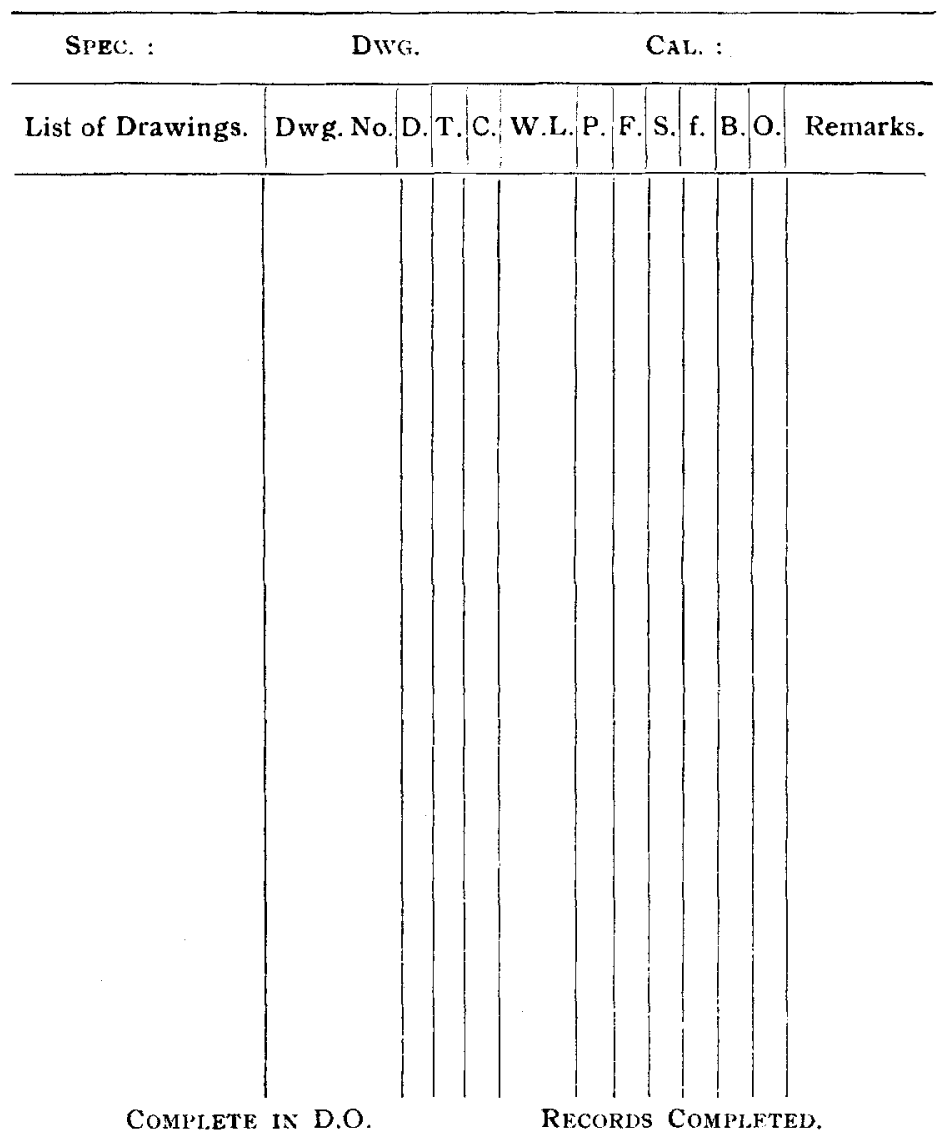

Fis 3. 
Issue No. 24.

8 Sets.

\section{DETAILED SCHEDULE.}

FOR ORDERING

PLATES, ANGLES \& BARS.

Order \& W. No, $12 /$ E17/L2.
Section: Tender Frame, Stegl Plates,

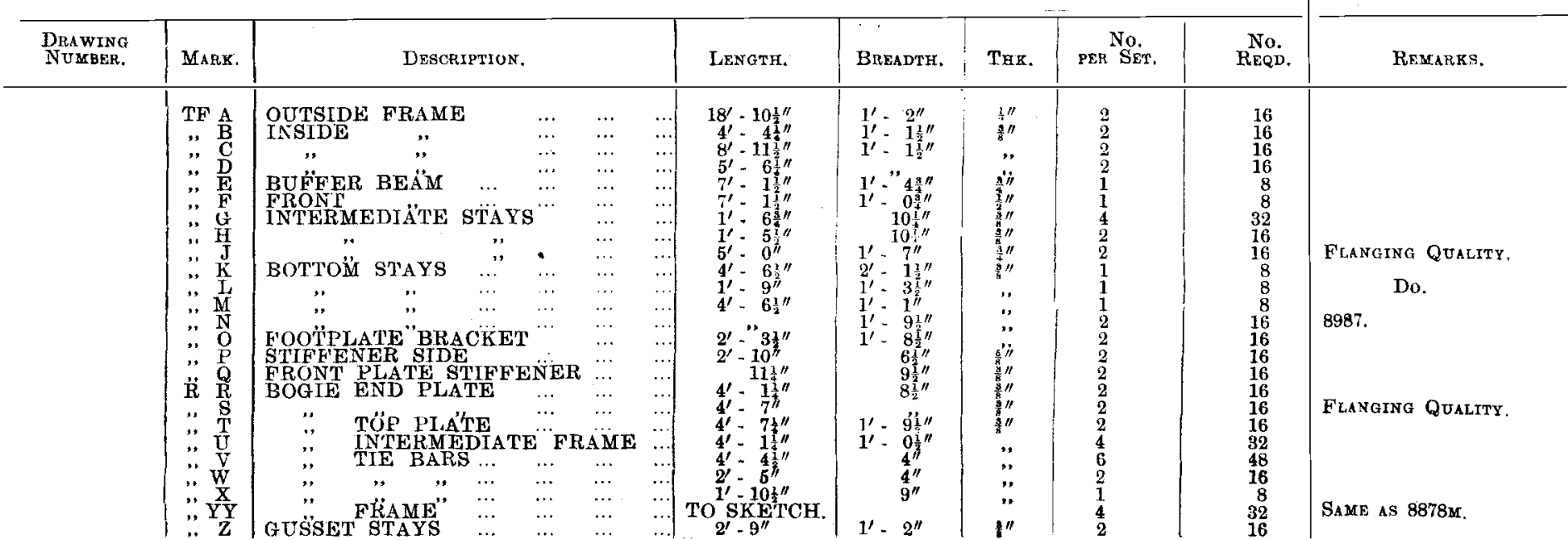

BRITISE STANDARD SPECIFICATION, REPORT No, 24.

SPECIFICATION NO. 17 .
5 SHOP.

11 sHop.

12 SHOP.

28 SHOP.

29 SHOP.

130 SHOP.

SAW MILLS.

COMOTIVE WORKS

STORE.

SCOTSWOOD STORE.

o.s.o. 


\section{ORDER OF BUILDING ENGINE.}

I Frames, frame stays, motion plate, hornblocks, spring hanger brackets, drag box plate, and stays.

2 Dome and cover, boiler clothing, firebars, brake gear, buffer beams, cylinders, valve chest with covers, drain cocks, blower and operating rods.

3. Superheater and body, axleboxes and lubricators, cylinder clothing, hand reversing gear, drag links, etc., steam distributing valves, steam reversing gear, slidebars and crossheads, slide rod and valve spindle.

4. Firebars and carriers, ashpan, damper and rods, rocking grate, firedoor ring and fittings, injectors, feed and delivery pipes, running plate, sandboxes, steps and guards, etc., running springs, valve gear.

5. Smokebox, chimney and spark arrester, feed pump and valve, smokebox door and fittings, steam pipes (outside), steam sanding gear, wheels and tyres, connecting rods, coupling rods, exhaust pipes.

6. Drawbar gear, tanks, bunkers, cab and handrails, pistons and gear.

7. Couplings, fog signal gear, rear end plate, lubricating system, mechanical lubricator.

8. Buffers, cowcatcher, lamp irons, bell, lamps, etc., safety chains.

FIG. 5. 


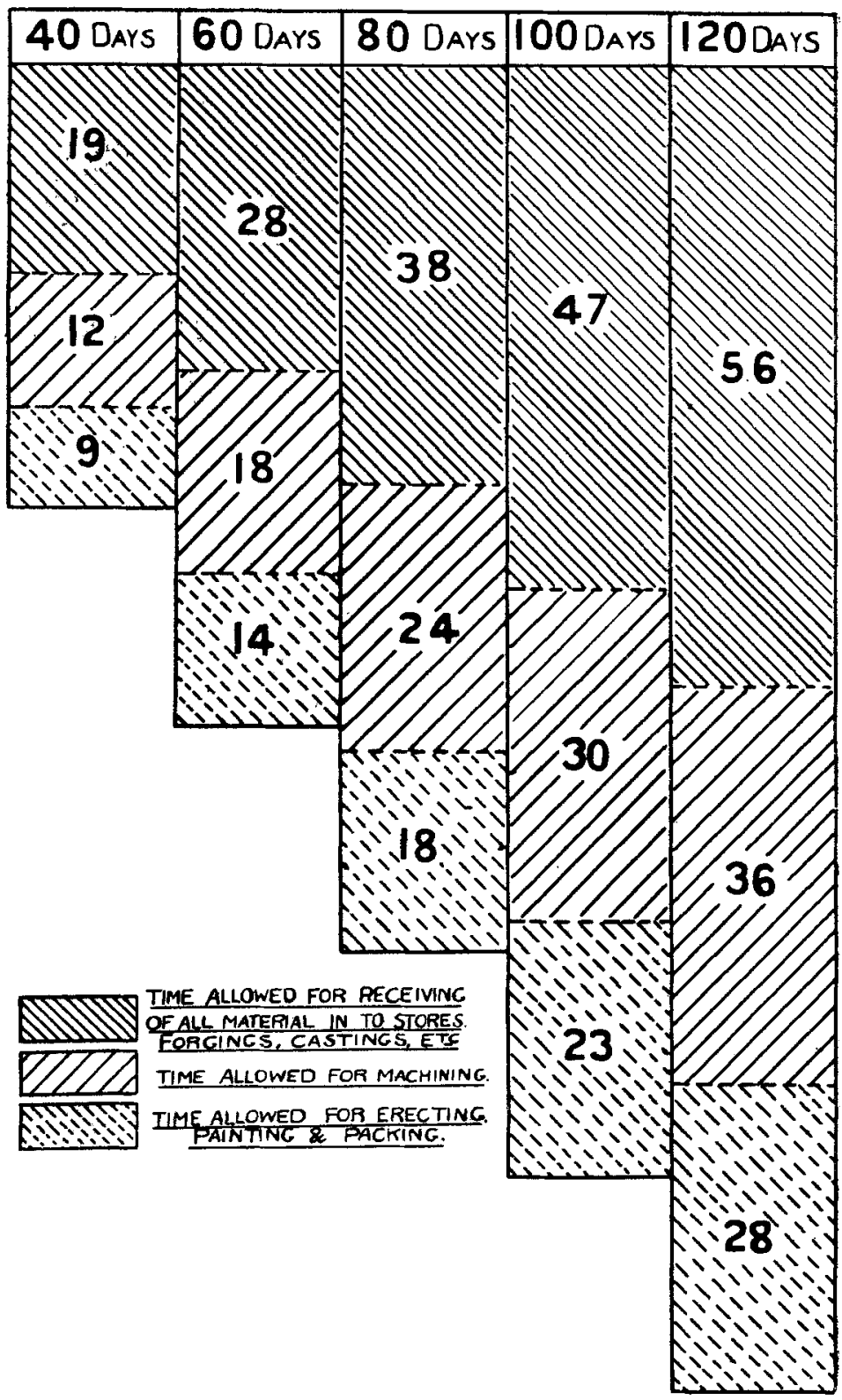

FIG. 6. 
JOURNAL OF THE INST. OF LOCO. ENGINEERS.

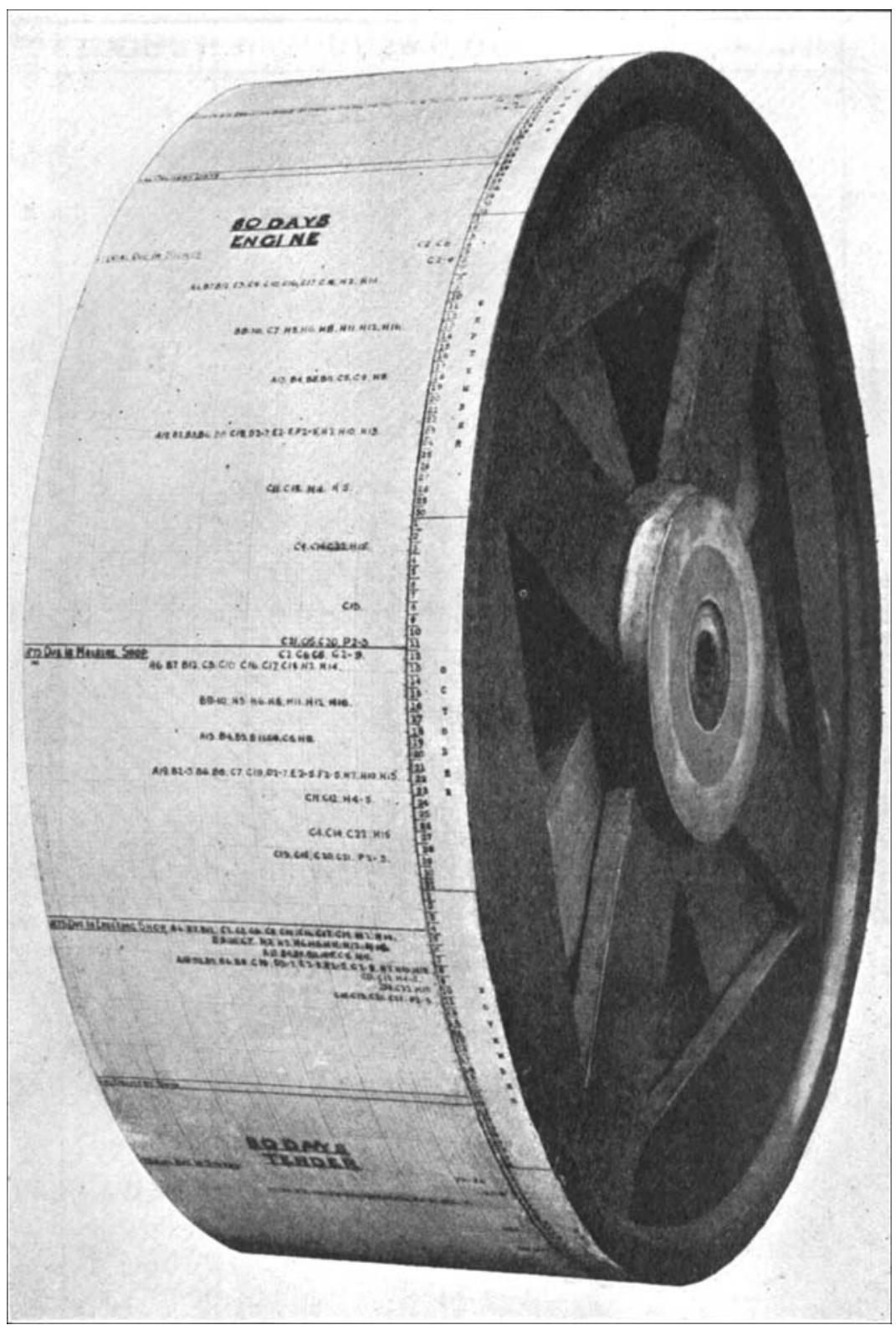

Fig. 7 . 


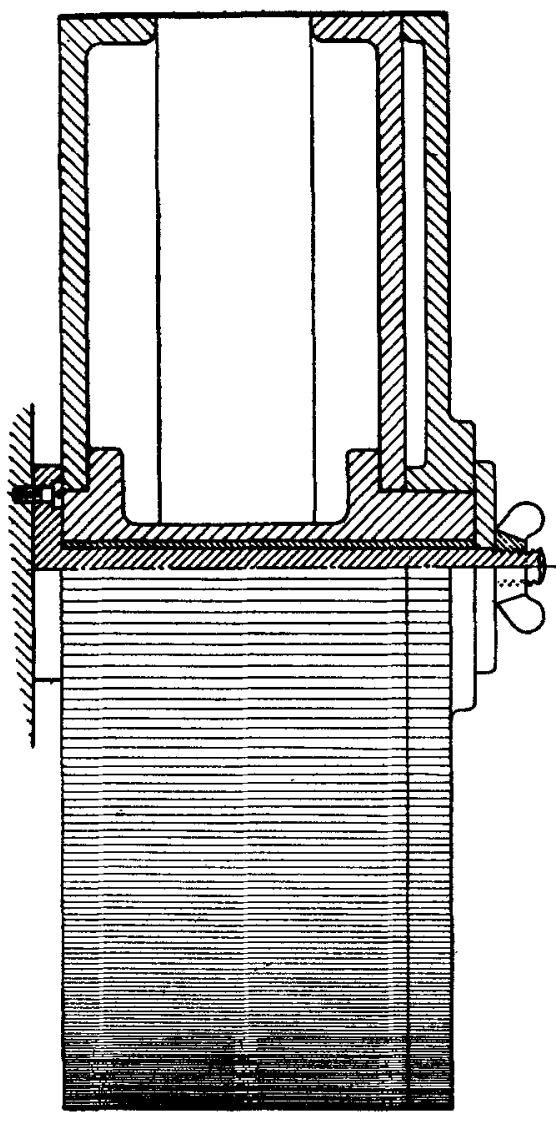

60 DAYS ENGINE

\begin{tabular}{|c|c|}
\hline FRAMERLATES, MQRURATES: & 1 \\
\hline 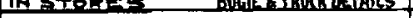 & \\
\hline 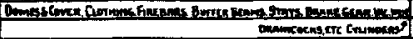 & \\
\hline & \\
\hline 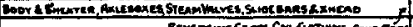 & 7 \\
\hline 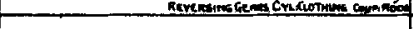 & $\frac{8}{9}$ \\
\hline & 10 \\
\hline 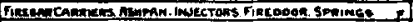 & Di \\
\hline Runming Putres: Valve Gean? & 12 \\
\hline & $\sqrt{3}$ \\
\hline & 14 \\
\hline 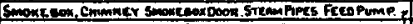 & \\
\hline 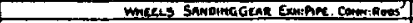 & 16 \\
\hline & 17 \\
\hline & 18 \\
\hline 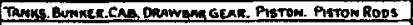 & 19 \\
\hline & 20 \\
\hline & 21 \\
\hline 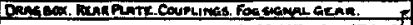 & 22 \\
\hline 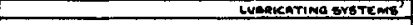 & 23 \\
\hline & 24 \\
\hline & 25 \\
\hline DUFFEES FIRLTOOLS TOQLS & 26 \\
\hline 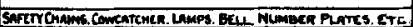 & 28 \\
\hline 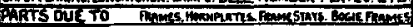 & 29 \\
\hline 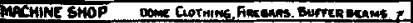 & 30 \\
\hline 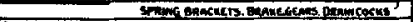 & 31 \\
\hline 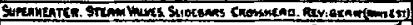 & I \\
\hline Cromoghs 7 & 2 \\
\hline 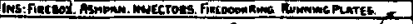 & 3 \\
\hline 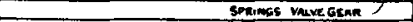 & 4 \\
\hline 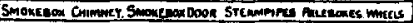 & 5 \\
\hline 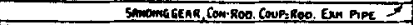 & 6 \\
\hline 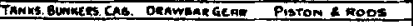 & 7 \\
\hline 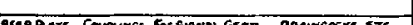 & 8 \\
\hline 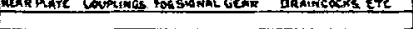 & 10 \\
\hline 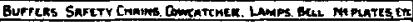 & 11 \\
\hline & 12 \\
\hline & 13 \\
\hline - PARTS OWE IN ERE & \\
\hline Therbink & 16 \\
\hline 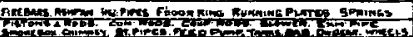 & 17 \\
\hline 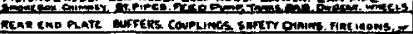 & \\
\hline 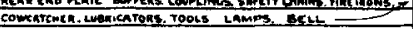 & $\frac{17}{20}$ \\
\hline & 2 \\
\hline & $\frac{22}{23}$ \\
\hline & \\
\hline & $\frac{35}{36}$ \\
\hline & 27 \\
\hline & 28 \\
\hline FIAAL DELIVEAY DATE & 29 \\
\hline
\end{tabular}

Fra. 8. 


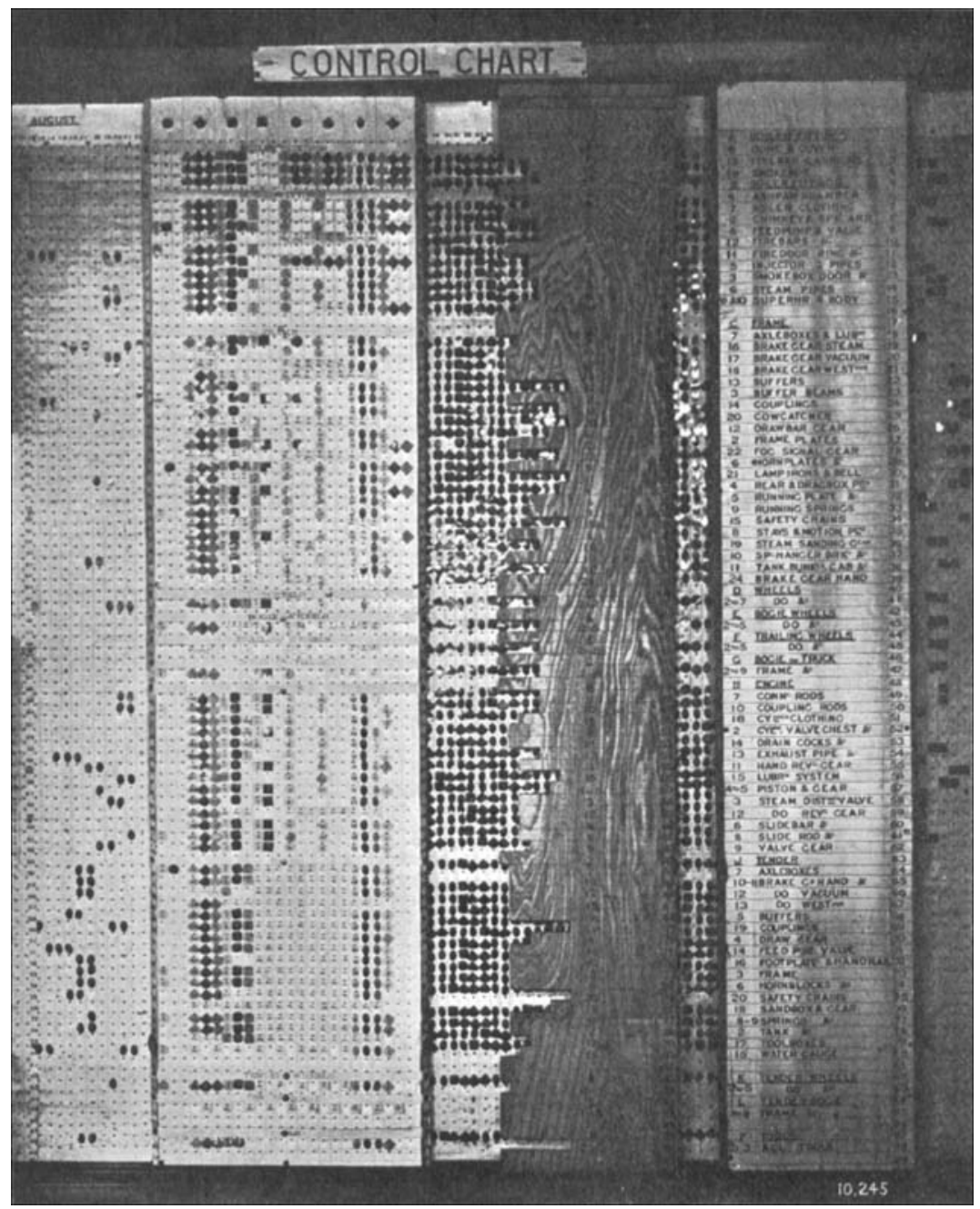

Fia. 9. 
PARTICULARS OF MACHINES.

PLANERS

SECTION

SHOI

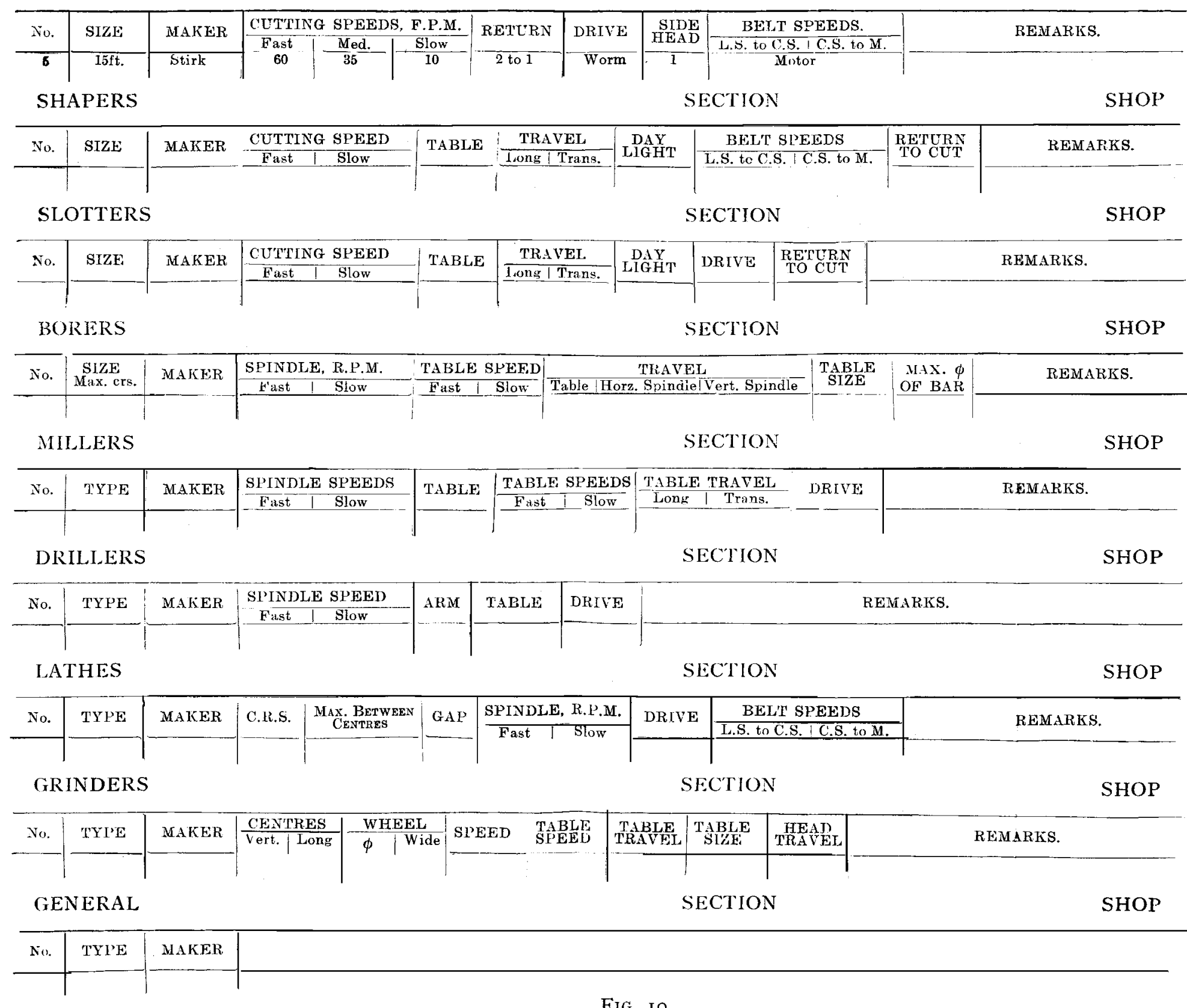

LIST OF DRAWINGS IN ORDER OF BLILDING (EO DAY PROGRAMME).

Drawings S'TART.

Frame Plates, Horns, Keeps and Wedges, Frames, Buffer Beams and Dragboxes 98

Dome and Corer, Boiler Clothing, Firebars, Buffer Beams, Frame Stays, Spring Hangers, Motion Plates, Brake Gear, Cvlinder and Valve Chests with Covers, Drain Cocks, Tank, Toolboxes and Cab, Buffers, Axleboxes, Feed Pipes, Valve and Gear, Footplates, Handrails and Lifting Gear, Springs and Rigging, Tender

Superheater and Body, Axleboxes and Lubricators, St. Bist. Valves, Slidebar and Crossheads, Slide Rod and Valve Spindle, Hand Rer. Gear, St. Rev. Gear,

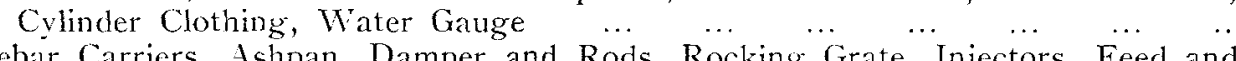

Firebar Carriers, Ashpan, Damper and Rods, Rocking Grate, Injectors, Feed and

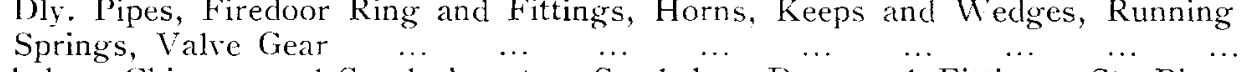

Smokebox, Chimney and Spark Arrester, Smokebox Door and Fittings, St. Pipes (Outs.), Feed Pump and Valve, St. Sanding Gear, Wheels, Engine Wheels, Conn. and Coupling Rods, Exh. Pipe, Blower and Operating Rods ... ...

Tanks, Bunkers, Cab, Handrails, Draw Bar Gear, Pistons for Crlinders, Piston

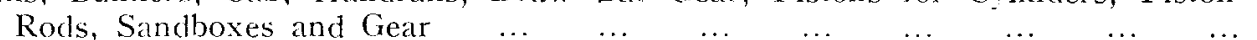

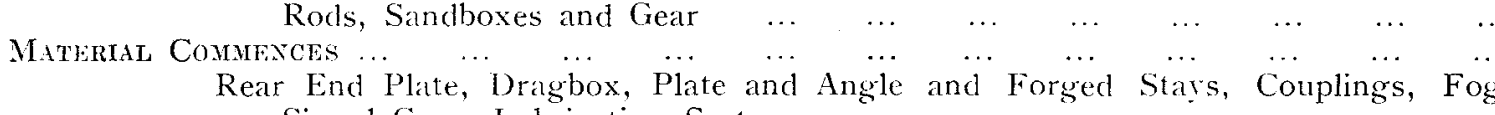

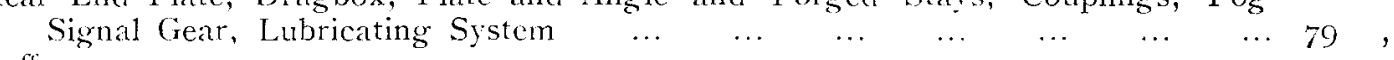
ALL Dratwives Is

Lamp Irons, Bell, Head and Tail Lamps, Number Plates, Safety Chains, Cowcatcher, all Tools, Couplings

Dachintag Conmexces

Dertivg Comire..

\begin{tabular}{|c|c|c|c|c|c|c|}
\hline$\cdots$ & $\cdots$ & $\ldots$ & $\ldots$ & .. & & \\
\hline$\cdots$ & $\cdots$ & $\cdots$ & $\ldots$ & .. & & \\
\hline & & $\cdots$ & $\ldots$ & .. & & \\
\hline
\end{tabular}

FIG. IT. 
FORM No. 8:

Sir W. G. Alimstrong, Whitworth \& Co., LtD.

Office Order...50r9........

Department.....Loco......... OPERATION LAY OUT.

Date....................

Working No....E29/H6..... Drawing No....39740..... Detail No.... I \& \& I2..... Description...

Section..." H "..... No...6...

No. of Details per Set... I R.H./r L.H.... No, of Sets...200/200... No. of Details Authorised...250/200

Description of Material Authorised.

Steel.

Date Completed.....

Crosshead

Date Commenced................................

pleted..............

Weight..

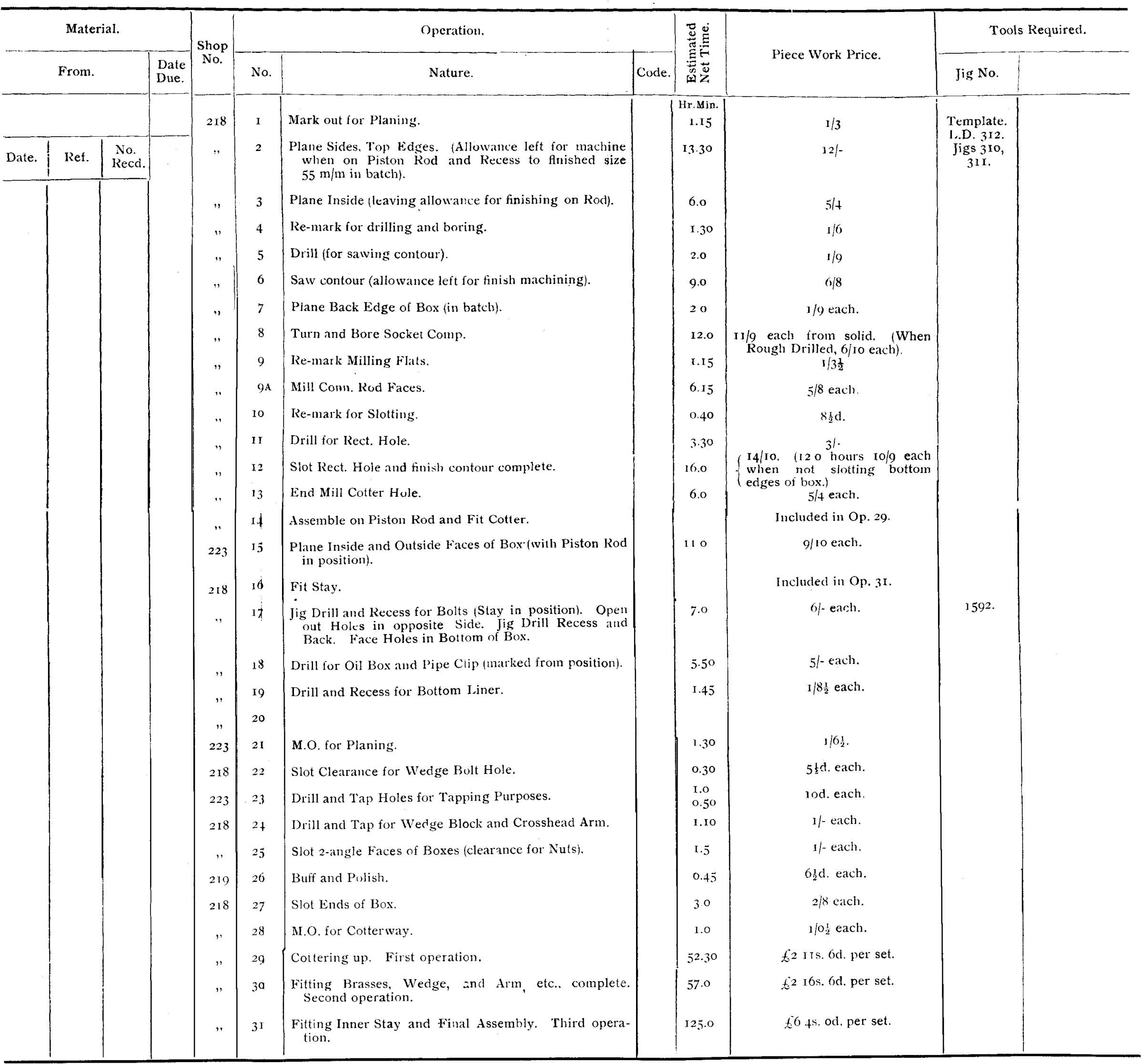

A similar Chart is issued to each Shop containing only the Operation Numbers concerning that Shop.

FIG. I 2. 


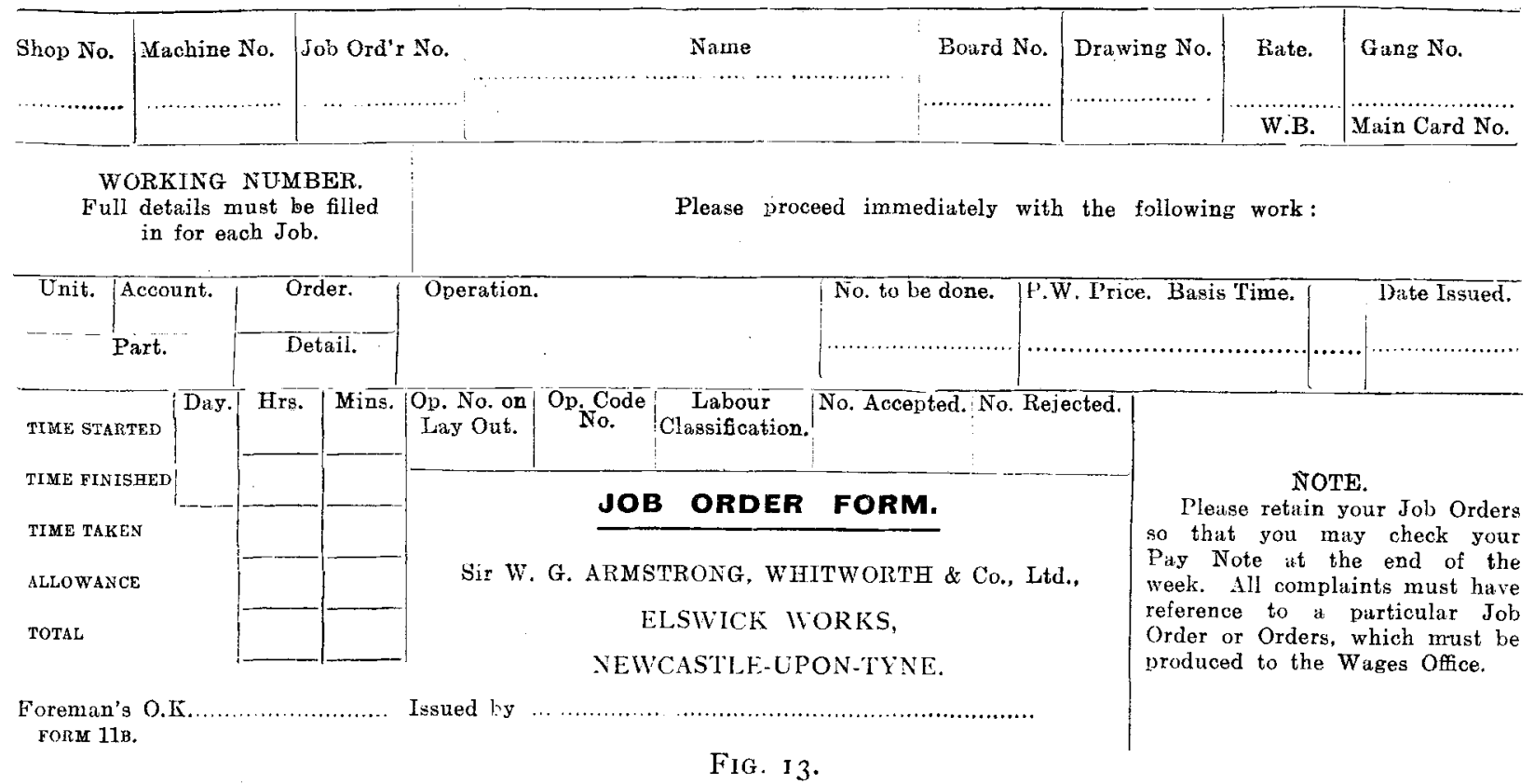

MEAN FEEDS AND SPEEDS WHEN USING HIGH SPEED TOOL STEEL.

Cutting speeds shown in $\mathrm{ft} . / \mathrm{min}$.

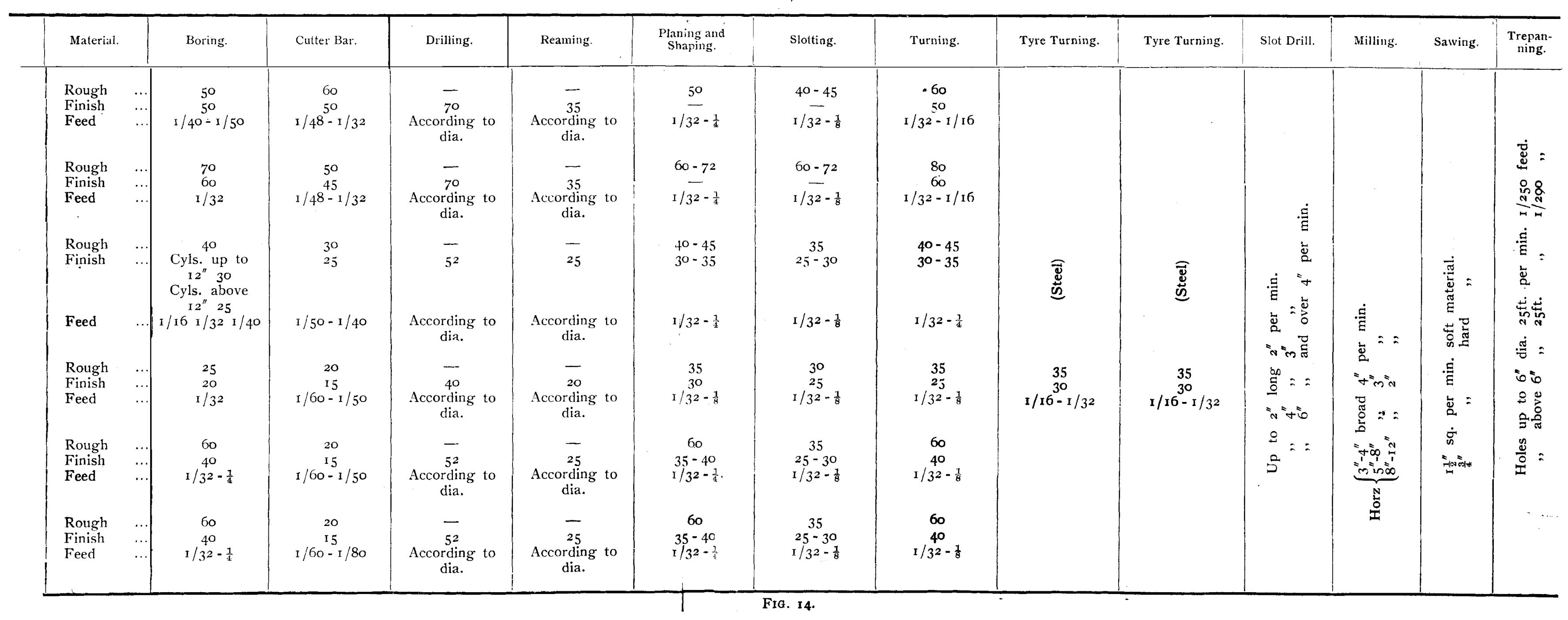


MODERN PRODdCTION AND COSTING METHODS-HOWELL. 447

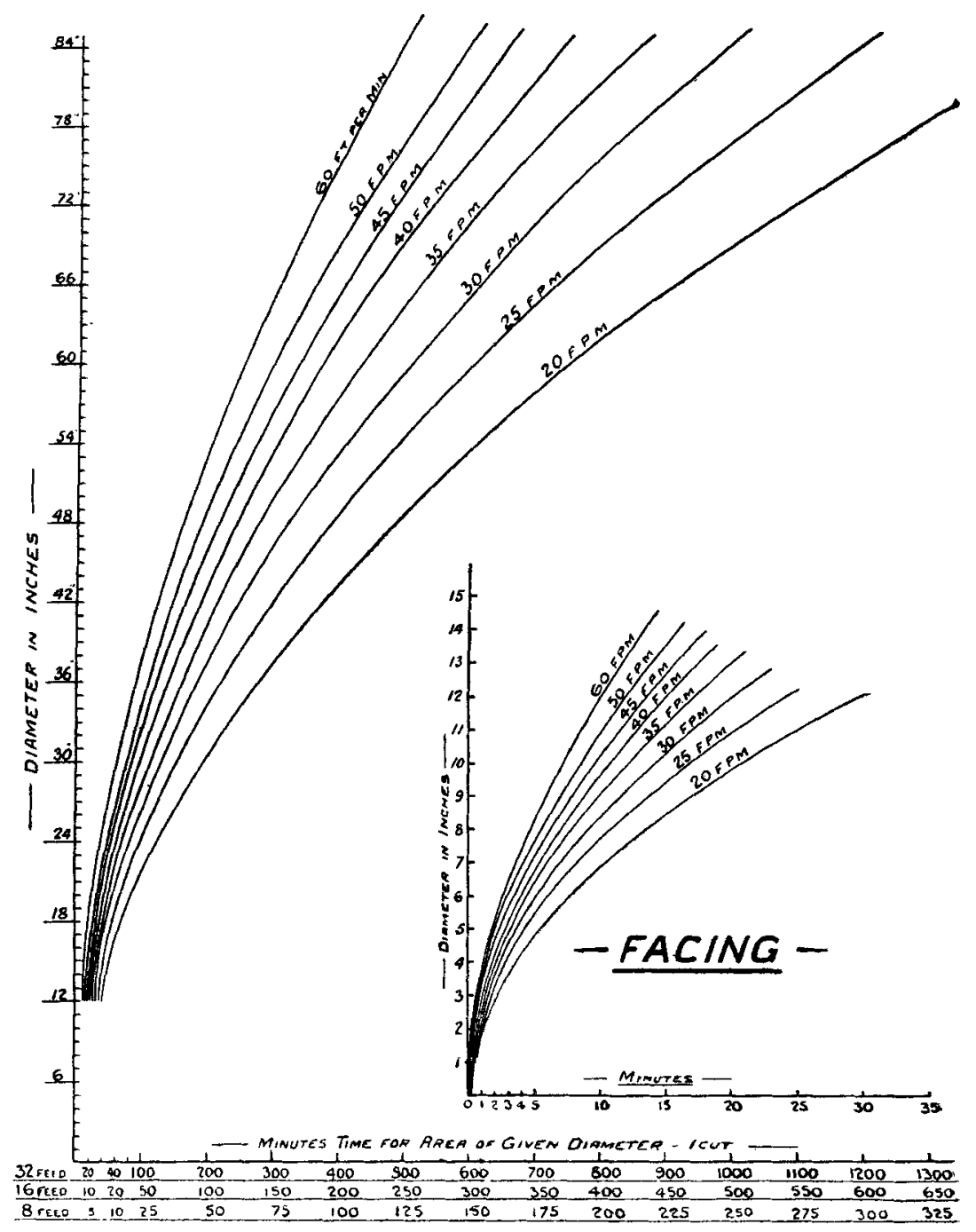

Fig. 15. 
$44^{8}$ JOURNAL OF TEE INST. OF LOOO. ENGINGERS.

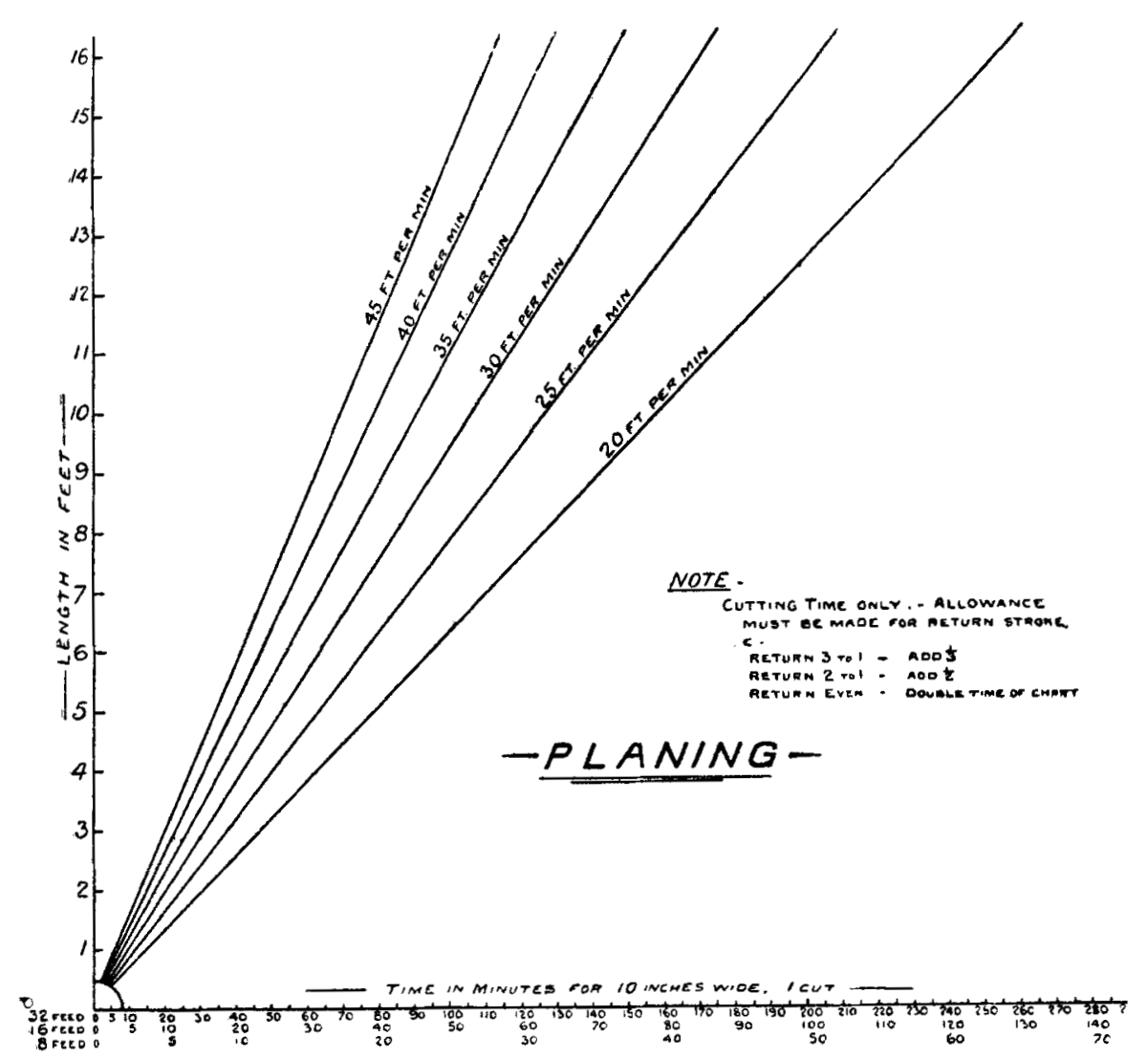

Fig. 16. 


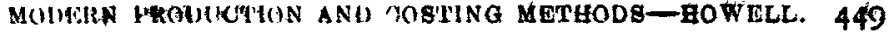

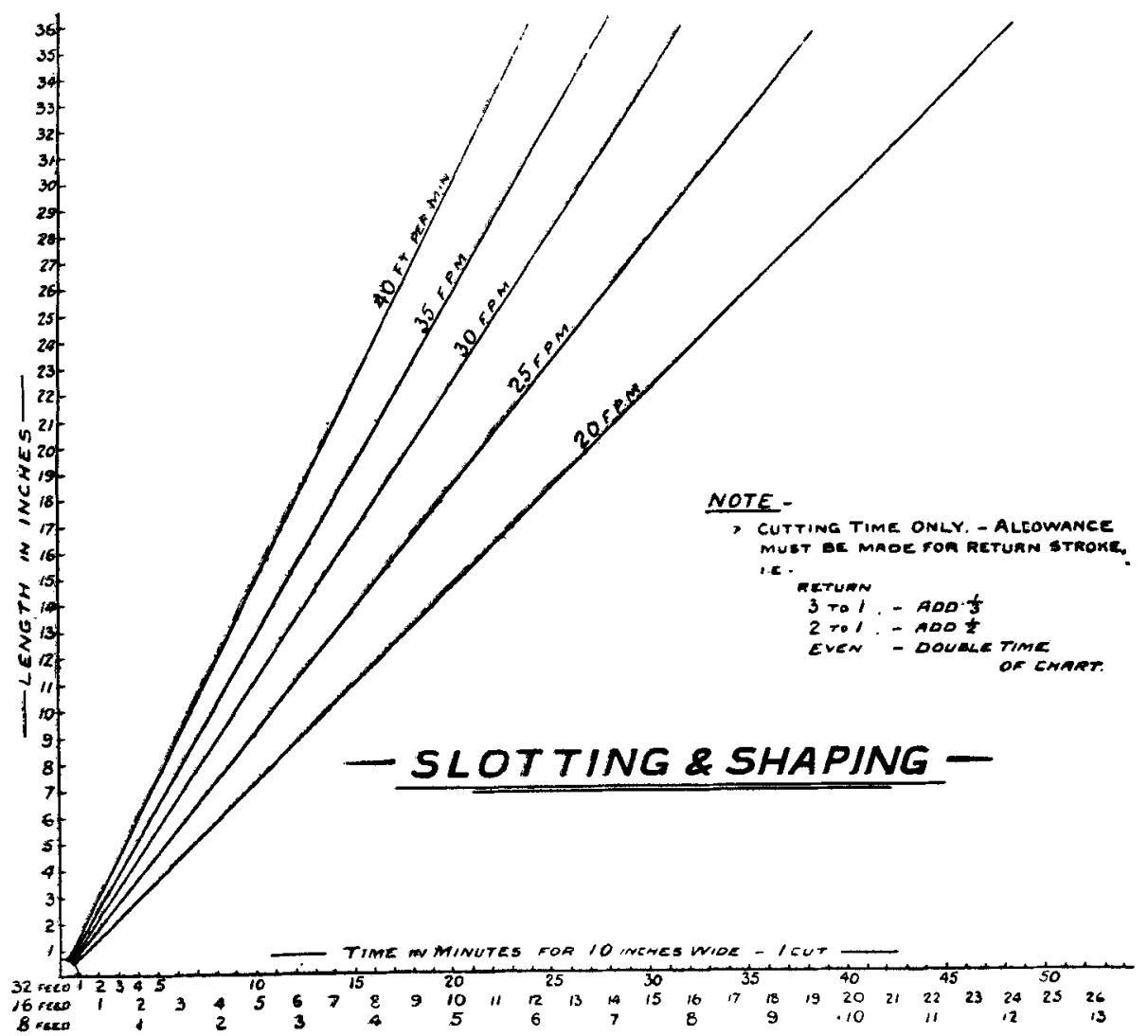

FIg. 17. 


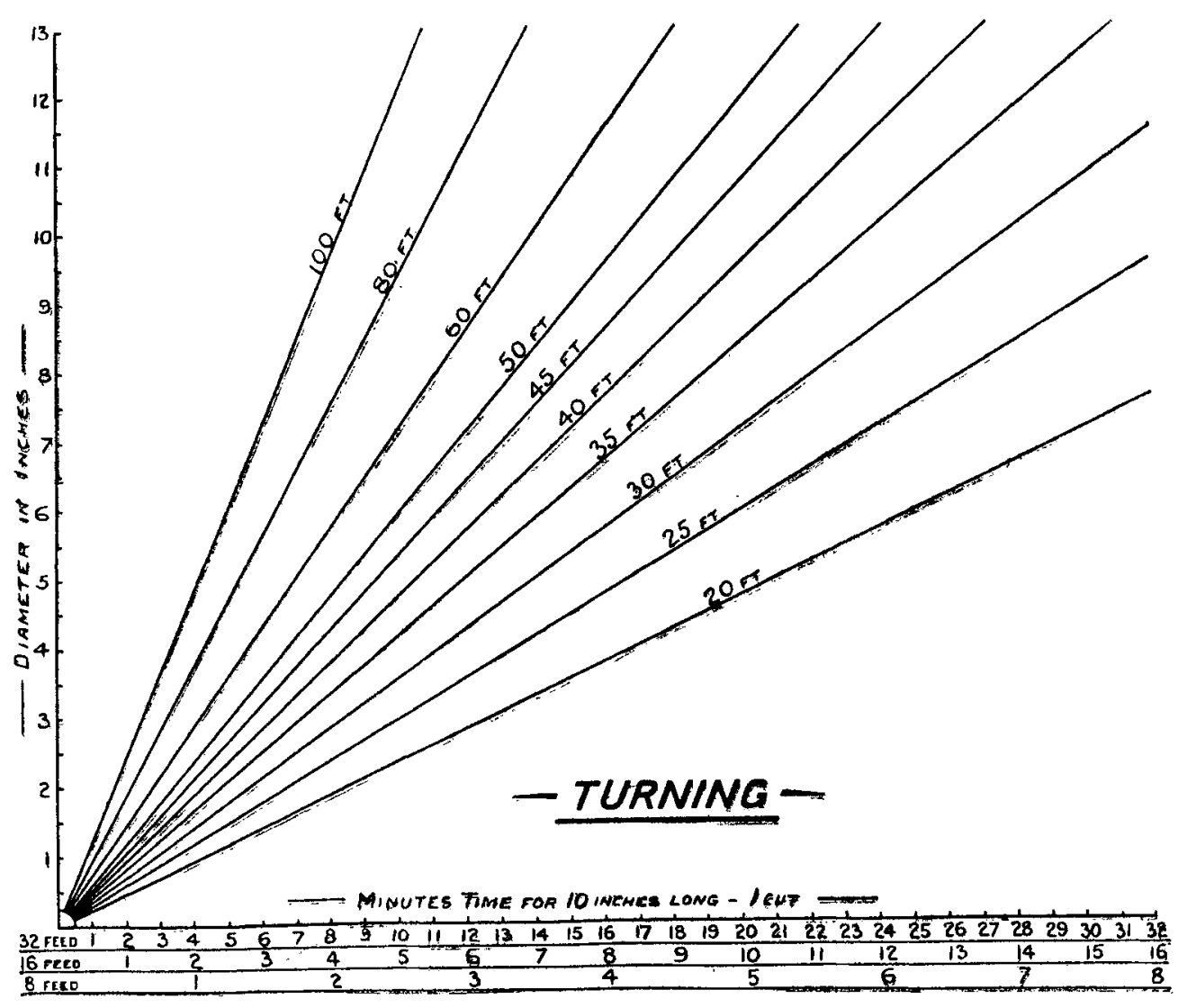

त

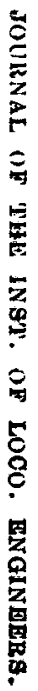


For Estimating, the following allowances have been made (on actual machining time only) :-

\section{PERCENTAGES ALLOWED.}

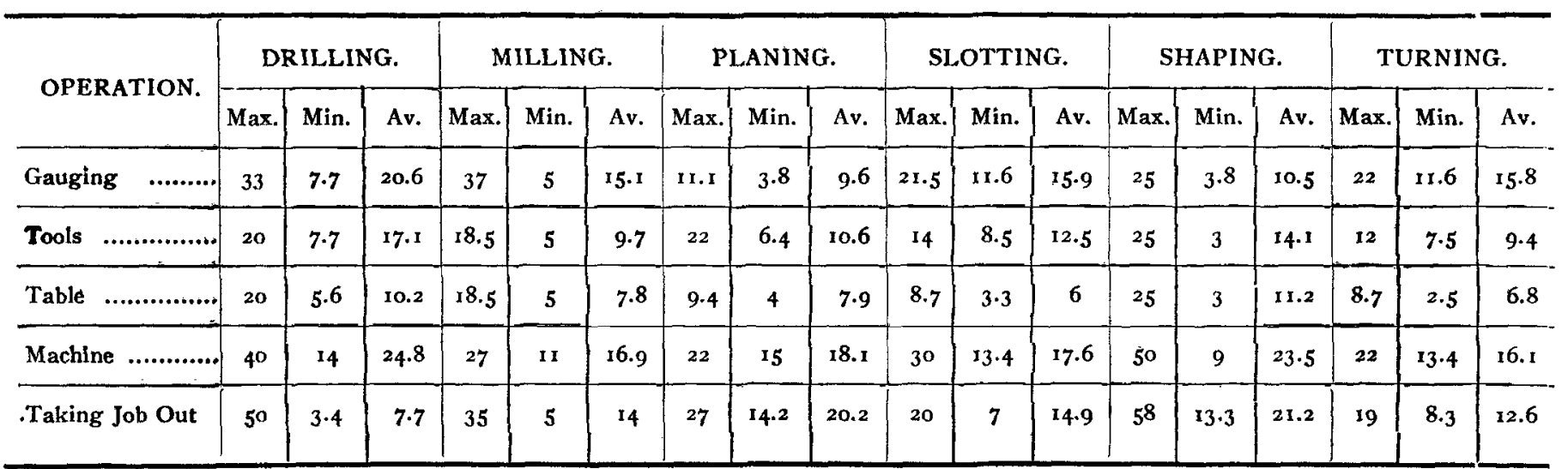

Fia. 19. 
TURNING.

TABLE OF CUTTING SPEEDS.

\begin{tabular}{|c|c|c|c|c|c|c|c|c|}
\hline $\begin{array}{l}\text { Feet } \\
\text { per } \\
\text { Min. }\end{array}$ & 20 & 25 & $3^{\circ}$ & 35 & 40 & 45 & 50 & 60 \\
\hline $\begin{array}{l}\text { Dia. } \\
\text { ins. }\end{array}$ & \multicolumn{8}{|c|}{ Revolutions per minute. } \\
\hline & & & & & & & & \\
\hline rin. & $7^{6}$ & 95 & II 4 & I 34 & I 53 & 172 & 191 & 229 \\
\hline I & $6 I$ & $7^{6}$ & 91 & 107 & 122 & ז 38 & 153 & 183 \\
\hline $\mathrm{I}_{2}^{\frac{1}{2}}$ in. & $5^{I}$ & 64 & $7^{6}$ & 89 & 102 & II 4 & 127 & I 53 \\
\hline 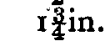 & 44 & 55 & 65 & $7^{6}$ & 87 & 98 & Iag & I3I \\
\hline 2in. & $3^{8}$ & 48 & 57 & 67 & $7^{6}$ & 86 & 95 & I 14 \\
\hline $2 \tan$. & 34 & 42 & $5^{x}$ & 59 & 68 & 76 & 85 & 102 \\
\hline $2 \frac{\mathrm{g}}{2} \mathrm{in}$. & $3 \mathrm{I}$ & $3^{8}$ & $4^{6}$ & 53 & 61 & 69 & $7^{6}$ & 92 \\
\hline $2 \frac{\overline{3}}{4}$ in. & 28 & 35 & 42 & 49 & 55 & 62 & 69 & 83 \\
\hline 3 in. & 25 & $3^{2}$ & $3^{8}$ & 44 & $5^{I}$ & 57 & 64 & $7^{6}$ \\
\hline $3 \frac{1}{4} \mathrm{in}$. & 23 & 29 & 35 & $4 \mathrm{r}$ & 47 & 53 & 59 & $7^{\circ}$ \\
\hline $3 \frac{1}{2}$ in. & 22 & 27 & 33 & $3^{8}$ & 44 & 49 & 54 & 65 \\
\hline $3 \frac{3}{4} \mathrm{in}$. & 20.3 & 25 & 30 & $3^{6}$ & $4 r$ & 46 & $5^{I}$ & $6 \mathrm{r}$ \\
\hline 4 in. & 19. x & 24 & 29 & 33 & $3^{8}$ & 43 & $4^{8}$ & 57 \\
\hline $4 \frac{1}{2} \mathrm{in}$. & 17 & 21 & 25 & $3^{\circ}$ & 34 & $3^{8}$ & 42 & $5^{I}$ \\
\hline 5 in. & $15 \cdot 3$ & I9. I & 23 & 27 & 30 & 34 & $3^{8}$ & 46 \\
\hline $5 \frac{1}{2}$ in. & 13.9 & 17.4 & 20.8 & 24 & 28 & $3 \mathbf{I}$ & 35 & 42 \\
\hline 6 in. & 12.7 & I 5.9 & I9. I & 22 & 25 & 28 & $3^{2}$ & $3^{8}$ \\
\hline $6 \frac{1}{2}$ in. & I 1.7 & 14.7 & 17.6 & 20.5 & 23 & 26 & 29 & 35 \\
\hline $7^{i n}$. & 10.9 & I 3.6 & I6.4 & I9. I & 22 & 25 & 27 & 33 \\
\hline $7 \frac{1}{2}$ in. & 10.2 & I 2.7 & r 5.3 & I 7.8 & 20.4 & 23 & 25 & $3^{I}$ \\
\hline 8 in. & 9.5 & II. 9 & 14.3 & I6.7 & 19. I & 21 & 24 & 29 \\
\hline 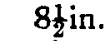 & 9.0 & 11.2 & 13.5 & I 5.7 & 18 & 20.2 & 22 & 27 \\
\hline gin. & 8.5 & ro.6 & 12.7 & 14.9 & 17 & I9. I & $2 \mathrm{I} . z$ & 25 \\
\hline $9 \frac{1}{2}$ in. & 8 & IO & 12.0 & 14.0 & I6. I & I8. I & 20.1 & 24 \\
\hline roin. & 7.6 & 9.5 & I 1.5 & $13 \cdot 36$ & I 5.27 & I 7.2 & 19. $\mathrm{r}$ & 23 \\
\hline I rin. & 6.9 & 8.7 & 10.4 & 12.2 & I 3.9 & I 5.6 & $17 \cdot 4$ & 20.8 \\
\hline I $2 \mathrm{in}$. & 6.4 & 7.9 & $9 \cdot 5$ & ร1. 6 & 2.7 & I 4.3 & 15.9 & 19. I \\
\hline I $3^{\text {in. }}$ & 5.9 & $7 \cdot 3$ & 8.8 & 10.3 & II 8 & I 3.2 & r. 4.7 & 17.6 \\
\hline I 4 in & 5.4 & 6.8 & 8.2 & $9 \cdot 5$ & 10.9 & I 2.3 & 13.6 & 16.4 \\
\hline$x_{5}$ in. & $5 \cdot \pi$ & 6.4 & 7.6 & 8.9 & I0. 2 & I I. 4 & I 2.7 & 15.3 \\
\hline I $6 \mathrm{in}$. & 4.8 & 6 & 7.16 & 8.3 & $9 \cdot 5$ & 10.7 & II.9 & 14.3 \\
\hline r $7^{\mathrm{in}}$ & 4.5 & 5.6 & 6.7 & 7.9 & 9.0 & IO. $\mathrm{r}$ & Ir. 2 & 13.5 \\
\hline
\end{tabular}

(Continued on page 453.) 
MODERN PRODUCTION AND COSTING METHODS-HOWELL. 453

(Continued from page 452.)

\begin{tabular}{|c|c|c|c|c|c|c|c|c|}
\hline $\begin{array}{l}\text { Feet } \\
\text { per } \\
\text { Min. }\end{array}$ & 20 & 25 & $3^{\circ}$ & 35 & 40 & 45 & $.5^{\circ}$ & 60 \\
\hline $\begin{array}{l}\text { Dia. } \\
\text { ins. }\end{array}$ & \multicolumn{8}{|c|}{ Revolutions per minute. } \\
\hline I $8 \mathrm{in}$. & 4.2 & $5 \cdot 3$ & 6.3 & 7.4 & 8.5 & 9.5 & 10.6 & 12.7 \\
\hline rgin. & 4 & 5 & 6.0 & 7.0 & 8.0 & 9.0 & 10.0 & I 2.0 \\
\hline 2oin. & 3.8 & 4.8 & $5 \cdot 7$ & 6.68 & 7.6 & 8.6 & 9.5 & II. 4 \\
\hline $2 \mathrm{Iin}$. & 3.6 & 4.5 & 5.4 & 6.3 & $7 \cdot 3$ & 8.2 & 9.1 & 10.9 \\
\hline 22 in. & $3 \cdot 4$ & $4 \cdot 3$ & 5.2 & 6. I & 6.9 & 7.8 & 8.7 & 10.4 \\
\hline 23 in. & $3 \cdot 3$ & 4. I & 5.0 & 5.8 & 6.6 & $7 \cdot 5$ & 8.3 & 10.0 \\
\hline 24 in. & 3.2 & 4.0 & $4 \cdot 7$ & 5.5 & 6.3 & $7 \cdot 16$ & 79 & $9 \cdot 5$ \\
\hline 25 in. & 3.1 & 3.8 & 4.6 & $5 \cdot 3$ & 6.I & 6.9 & 7.6 & \\
\hline $26 \mathrm{in}$ & 2.9 & $3 \cdot 7$ & 4.4 & 5.1 & 5.84 & 6.6 & $7 \cdot 3$ & \\
\hline 27 in. & 2.8 & $3 \cdot 5$ & 4.2 & 5.0 & $5 \cdot 7$ & 6.4 & 7.1 & \\
\hline 28 in. & 2.7 & 3.4 & $4 . I$ & 4.8 & $5 \cdot 5$ & 6.1 & 6.8 & \\
\hline 29in. & 2.6 & $3 \cdot 3$ & 4.0 & 4.6 & $5 \cdot 3$ & 5.9 & 6.6 & \\
\hline 3oin. & 2.5 & 3.2 & 3.8 & 4.5 & 5.1 & 5.7 & 6.4 & \\
\hline 3 in. & 2.4 & 3.0 & $3 \cdot 7$ & $4 \cdot 3$ & 4.9 & $5 \cdot 5$ & 6.1 & \\
\hline $3^{2 \text { in. }}$ & 2.2 & 3.0 & 3.6 & 4.2 & 4.8 & 5.4 & 5.9 & \\
\hline $33^{\text {in. }}$ & $2 \cdot 3^{2}$ & 2.8 & 3.5 & 4.0 & 4.6 & 5.2 & 5.8 & \\
\hline 34 in. & 2.2 & 2.8 & $3 \cdot 3$ & 3.9 & $4 \cdot 5$ & 5.0 & 5.6 & \\
\hline $35^{\text {in. }}$ & 2.18 & 2.8 & 3.2 & 3.8 & 4.3 & 4.9 & 5.4 & \\
\hline $36 \mathrm{in}$. & 2.1 & 2.6 & 3.2 & 3.7 & 4.2 & 4.8 & $5 \cdot 3$ & \\
\hline $37^{\text {in }}$ & 1.84 & 2.3 & $2.7^{6}$ & 3.2 & 3.68 & 4. $r$ & 4.6 & \\
\hline 5oin. & 1.52 & 1.9 & 2.3 & 2.67 & 3.0 & 3.4 & 3.8 & \\
\hline 6oin. & I. 27 & $1 . \overline{6}$ & I. 9 & 2.2 & $2.5^{6}$ & 2.9 & 3.2 & \\
\hline 7oin. & 1.09 & I. 37 & $1 . \overline{6}$ & 1.9 & 2.16 & 2.4 & 2.7 & \\
\hline 8oin. & .95 & 1.2 & I. 4 & 1. 68 & I.9 & 2. I & 2.4 & \\
\hline goin. & .84 & I.06 & 1. 27 & I. $4^{8}$ & I. 7 & 1.9 & 2. I & \\
\hline rooin. & .76 & .95 & I. 14 & I. 34 & I. 54 & 1.7 & 1.9 & \\
\hline I roin. & .69 & .86 & 1.0 & I. 22 & I. 4 & I. 57 & $\mathbf{x} .74$ & \\
\hline I 20 in. & .63 & .8 & .95 & I. I & I. 26 & 1.42 & $1.5^{8}$ & \\
\hline I zoin. & .58 & .73 & .87 & 1.03 & 1. 18 & I. $3^{2}$ & I. 47 & \\
\hline r 4oin. & .54 & .68 & $.8 \mathrm{I}$ & .96 & I.I & 1.23 & I. 36 & \\
\hline I 5 oin. & .51 & .63 & .76 & .89 & 1.02 & I. I 5 & 1.28 & \\
\hline I6oin. & .47 & .6 & .7 & .84 & .95 & I.07 & I. I9 & \\
\hline I8oin. & .42 & $\cdot 53$ & .63 & .74 & .85 & .95 & 1.06 & \\
\hline
\end{tabular}

FIG. 20. 
JOURNAL OF THE INST. OF LOCO. ENGINEERS.

\section{SLOTTING.}

Greatest number of strokes per minute 45 .

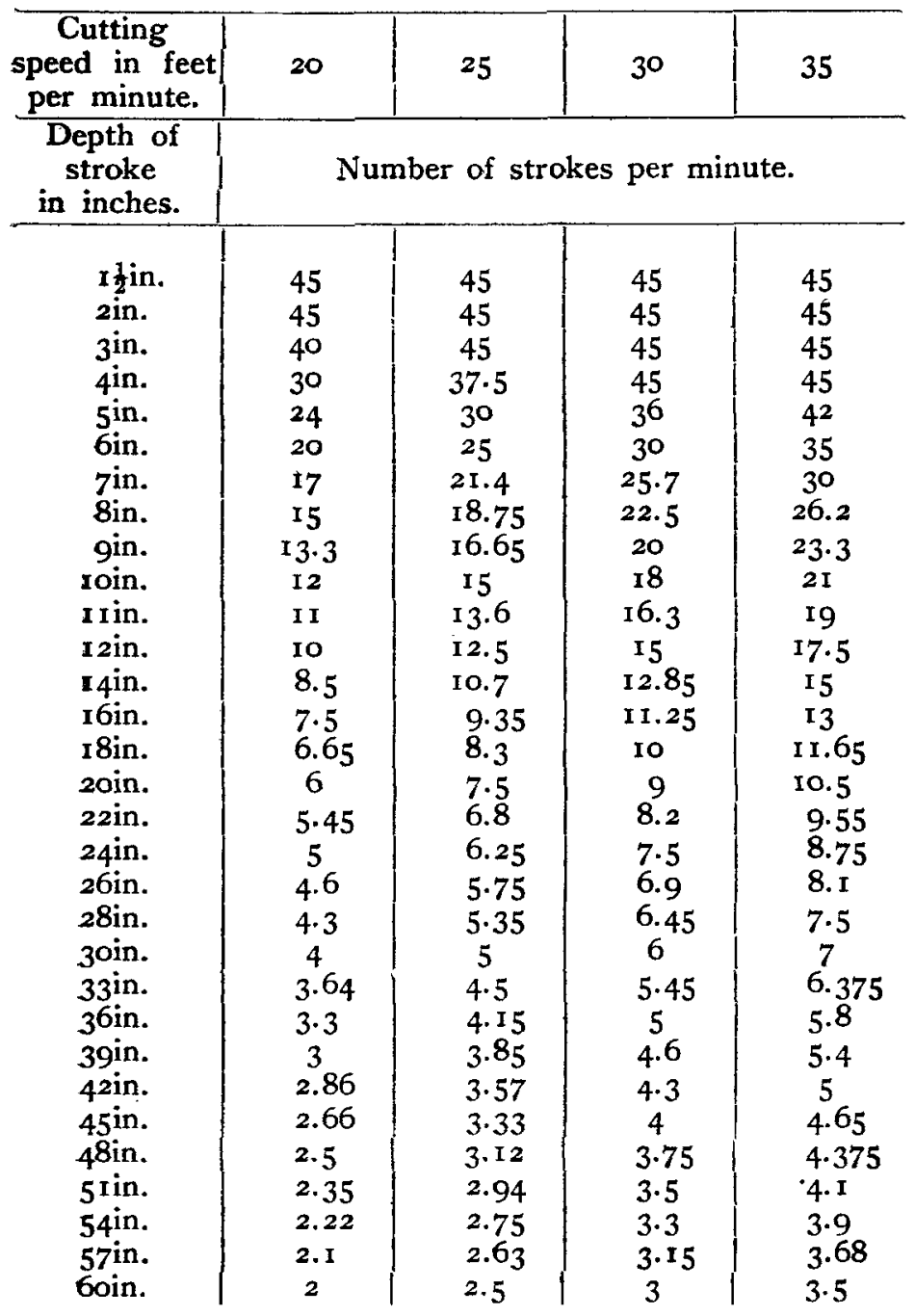

FIG. 2 I. 
MODERY PRODUOTION AND COSTING METHODS-HOWELL. 455

PLANING AND SHAPING.

Maximum number of strokes 80 per minute (return speed 2 to I).

\begin{tabular}{|c|c|c|c|c|}
\hline $\begin{array}{l}\text { Cutting } \\
\text { speed in feet } \\
\text { per minute. }\end{array}$ & 20 & 25 & 30 & 35 \\
\hline $\begin{array}{c}\text { Length of } \\
\text { stroke } \\
\text { in inches. }\end{array}$ & \multicolumn{4}{|c|}{ Number of strokes per minute. } \\
\hline 2in. & 80 & 80 & 80 & 80 \\
\hline in. & 53.25 & 66.5 & 80 & 80 \\
\hline $\begin{array}{l}\text { 4in. } \\
\text { sin. }\end{array}$ & 40 & $5^{\circ}$ & 60 & 70 \\
\hline sin. & $3^{2}$ & 40 & 48 & 56 \\
\hline 6in. & 27 & 33.25 & 40 & 46.5 \\
\hline 7 in. & 23 & 28.5 & $34 \cdot 3$ & 40.0 \\
\hline 8in. & 20 & 25 & 30 & 35 \\
\hline gin. & 18 & 22 & 26.6 & 31.0 \\
\hline Ioin. & I6 & 20 & 24 & 28 \\
\hline I in. & 14.5 & 18 & 21.8 & 25.4 \\
\hline I 2 in. & $13 \cdot 3$ & 16.5 & 20 & $23 \cdot 3$ \\
\hline I 4 in. & $1 \mathrm{I} .4$ & 14.25 & 17.1 & 20 \\
\hline I 6 in. & 10 & 12.5 & 15 & $17 \cdot 5$ \\
\hline I $8 \mathrm{in}$. & 8.9 & II & $13 \cdot 3$ & I $5 \cdot 5$ \\
\hline 2oin. & 8 & 10 & 12 & 14 \\
\hline 22 in. & 7.25 & 9. I & 10.9 & 12.7 \\
\hline 24 in. & 6.65 & 8.3 & 10 & 11.6 \\
\hline 26 in. & 6.15 & $7 \cdot 7$ & 9.25 & 10.75 \\
\hline 28in. & $5 \cdot 7$ & 7.15 & 8.6 & 10 \\
\hline 3oin. & $5 \cdot 3$ & 6.65 & 8 & $9 \cdot 3$ \\
\hline 33 in. & 4.85 & 6 & $7 \cdot 3$ & 8.5 \\
\hline $3^{6}$ in. & $4 \cdot 45$ & $5 \cdot 5$ & 6.65 & $7 \cdot 75$ \\
\hline 39in. & 4. I & 5.1 & 6.15 & $7 \cdot 3$ \\
\hline $4^{2 \mathrm{in} .}$ & 3.8 & 4.75 & $5 \cdot 7$ & 6.65 \\
\hline $45 \mathrm{in}$. & 3.55 & 4.45 & $5 \cdot 35$ & 6.2 \\
\hline $48 \mathrm{in}$. & $3 \cdot 3$ & 4.15 & 5 & 5.8 \\
\hline 5 rin. & 3.I & $3 \cdot 9$ & $4 \cdot 7$ & $5 \cdot 5$ \\
\hline $54 \mathrm{in}$. & & $3 \cdot 7$ & 4.44 & 5.2 \\
\hline 57 to 6 oin. & 2.75 & $3 \cdot 4$ & $4 . I$ & 4.8 \\
\hline 63 to $66 \mathrm{in}$. & 2.45 & 3.1 & 3.72 & $4 \cdot 3$ \\
\hline 69 to $7^{2 i n}$ & 2.25 & 2.8 & $3 \cdot 4$ & 4 \\
\hline 75 to 87 in. & 2 & 2.46 & 2.96 & 3.45 \\
\hline 90 to g9in. & 1.7 & 2.1 & 2.54 & 2.96 \\
\hline IO2 to I $20 \mathrm{in}$. & I. 4 & I.8 & 2.16 & 2.52 \\
\hline I 26 to I 5oin. & I. I 5 & I. 45 & I.74 & 2.0 \\
\hline 156 to $174 \mathrm{in}$ & I & 1.2 & $\mathrm{I} .45$ & I. 7 \\
\hline 180 to $192 \mathrm{in}$. & .86 & 1.07 & 1.29 & 1.5 \\
\hline
\end{tabular}




\section{DRILLING.}

Recommended for estimating drilling with high speed twist drills, adjusted table 50, 40, 25 and 20 feet per minute cutting speed.

\section{REVOLUTIONS PER MINUTE.}

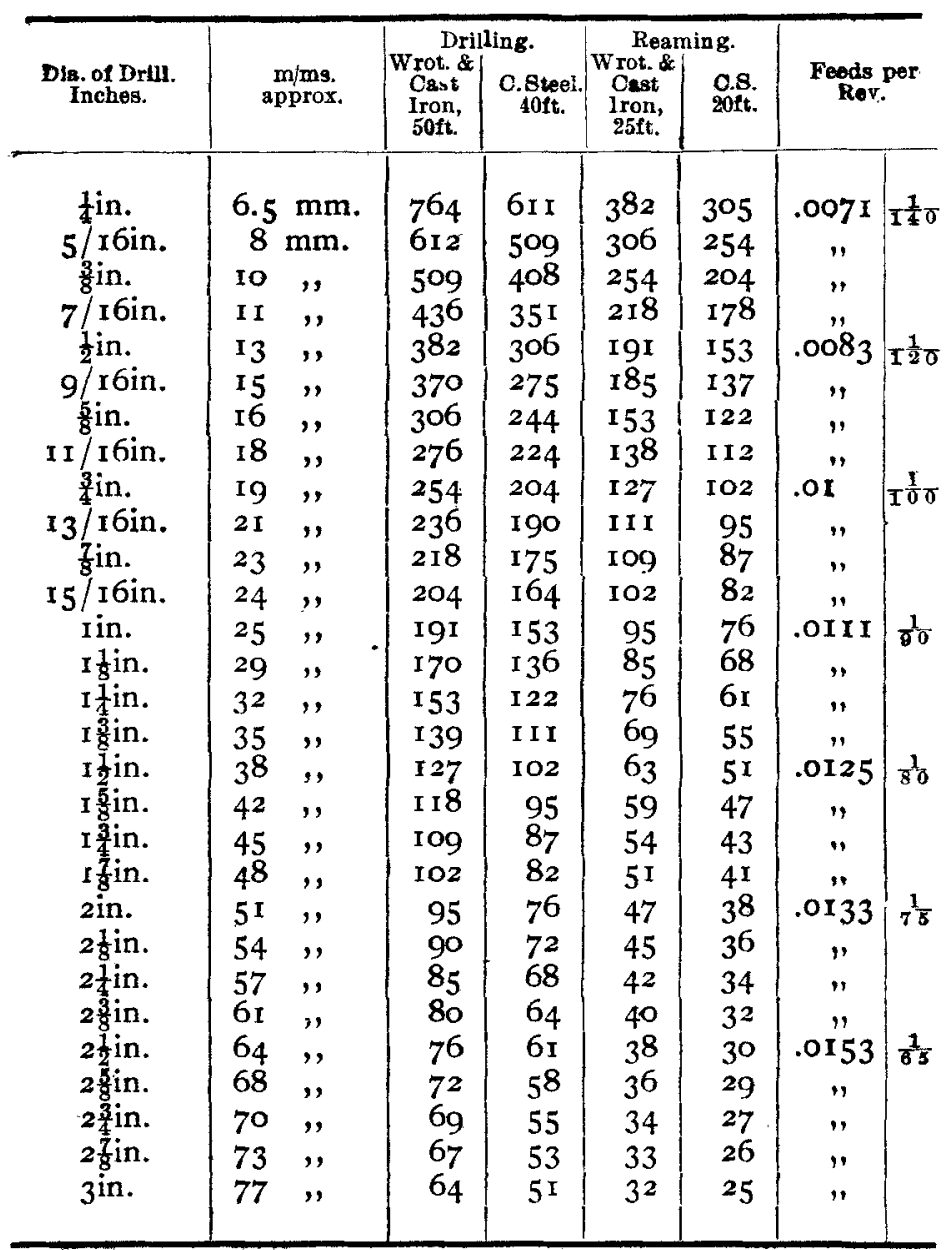

Frg. 23. 


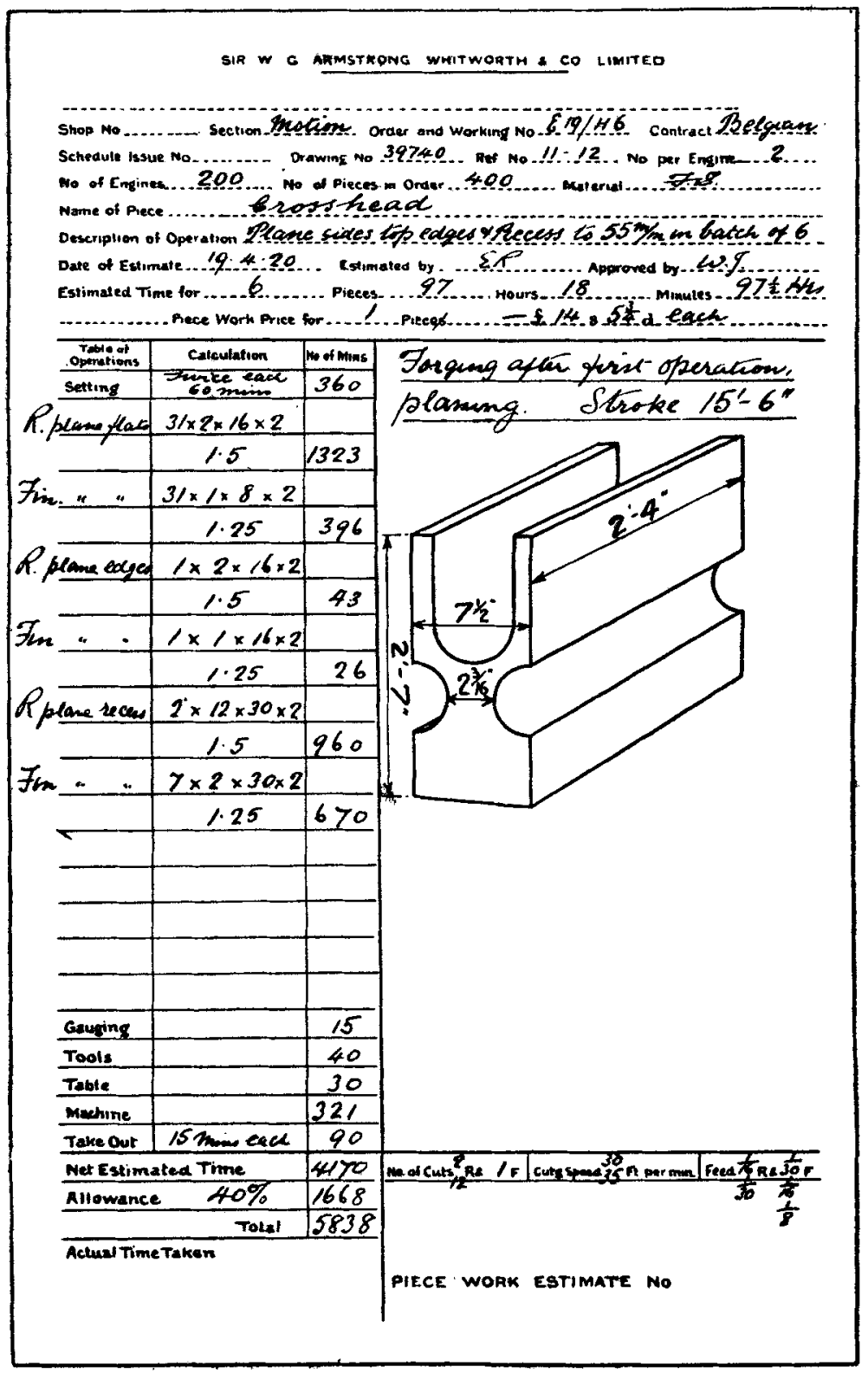

Fi19. 24. 
PINS (MACHINED COMPLETE).

\begin{tabular}{|c|c|c|c|c|c|c|c|c|c|}
\hline $\begin{array}{c}\text { Order } \\
\&\end{array}$ & $\begin{array}{l}\text { Item } \\
\text { No. }\end{array}$ & $\begin{array}{l}\text { Drawing } \\
\text { No. }\end{array}$ & \multicolumn{4}{|c|}{ DESCRIPTION. } & \multirow{2}{*}{$\frac{\text { ن. }}{1}$} & \multirow{2}{*}{ 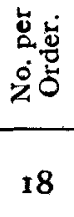 } & \multirow{2}{*}{$\begin{array}{l}\text { PRICE } \\
\text { EACH. } \\
2 / 2 \frac{1}{4}\end{array}$} \\
\hline $\mathrm{E}_{3} / \mathrm{C}_{12}$ & 16 & $3^{6076}$ & Hind Draw Bar Pin & $\ldots$ & $\begin{array}{l}\text { DIAM. } \\
21^{n}\end{array}$ & $\begin{array}{l}\text { LENGTH. } \\
1 I^{\circ} / 10^{\circ}\end{array}$ & & & \\
\hline $\mathrm{E}_{3} / \mathrm{G}_{3}$ & 2 & $3^{6788}$ & Bogie Centre Pin ... & & $1 \frac{t^{\prime \prime}}{8}$ & $10^{\prime \prime}$ & $\mathbf{I}$ & 18 & $x / 6 \frac{1}{2}$ \\
\hline $\mathrm{E}_{3} / \mathrm{H} 6$ & 20 & $3^{647^{\circ}}$ & Gudgeon Pin & & $34^{\prime \prime}$ & $73^{\prime \prime}$ & 2 & $3^{6}$ & $3 / 3 \frac{1}{2}$ \\
\hline $\mathrm{E}_{3} / \mathrm{HII}$ & 24 & 373 I I & Reversing Handle Pin & ... & $1 \frac{3}{8}$ & $3 \frac{3}{4}^{n}$ & $\mathbf{I}$ & 18 & $7 \frac{1}{2}$ \\
\hline
\end{tabular}

Era. 25. 


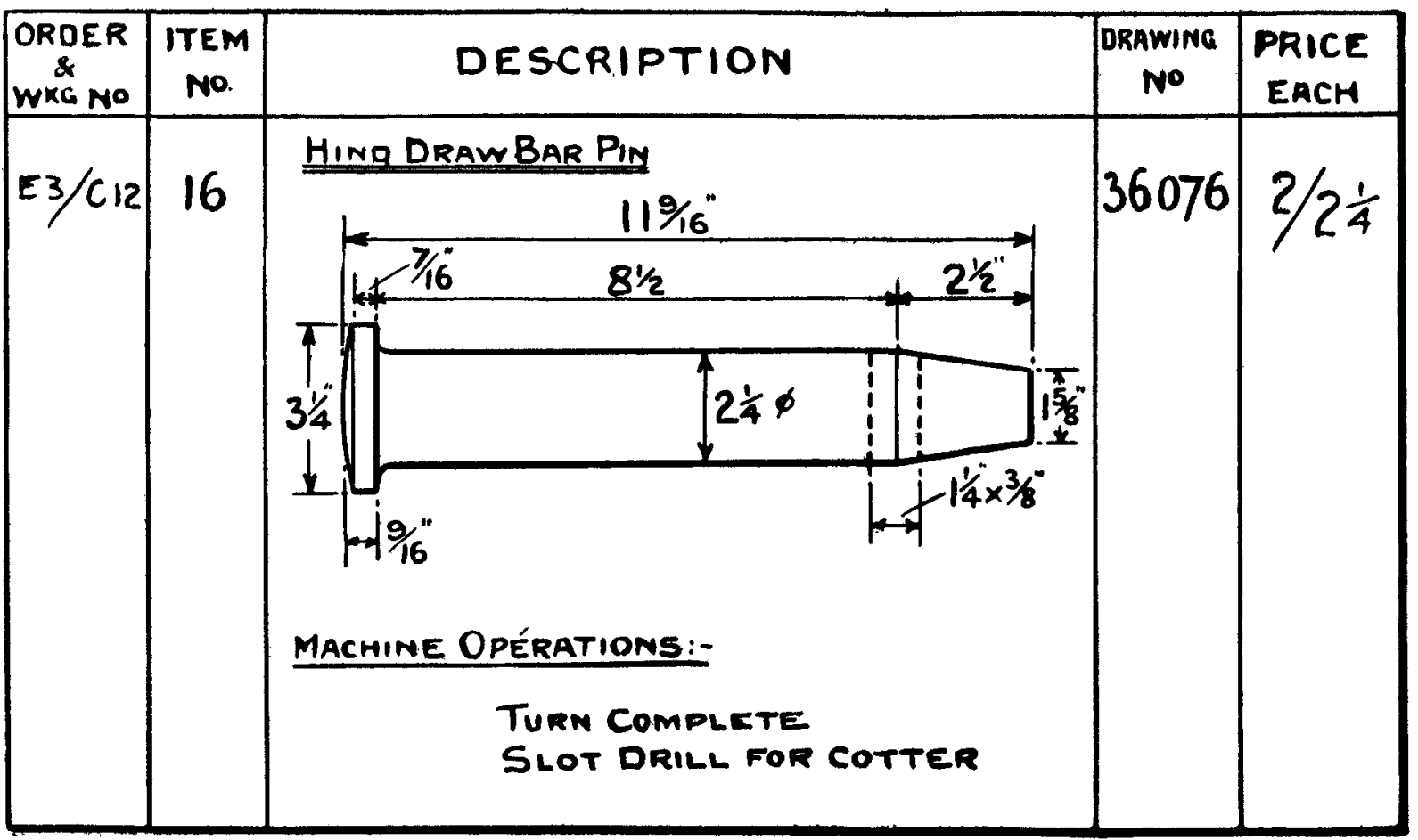

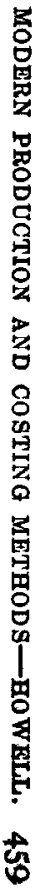

Fị. 26, 


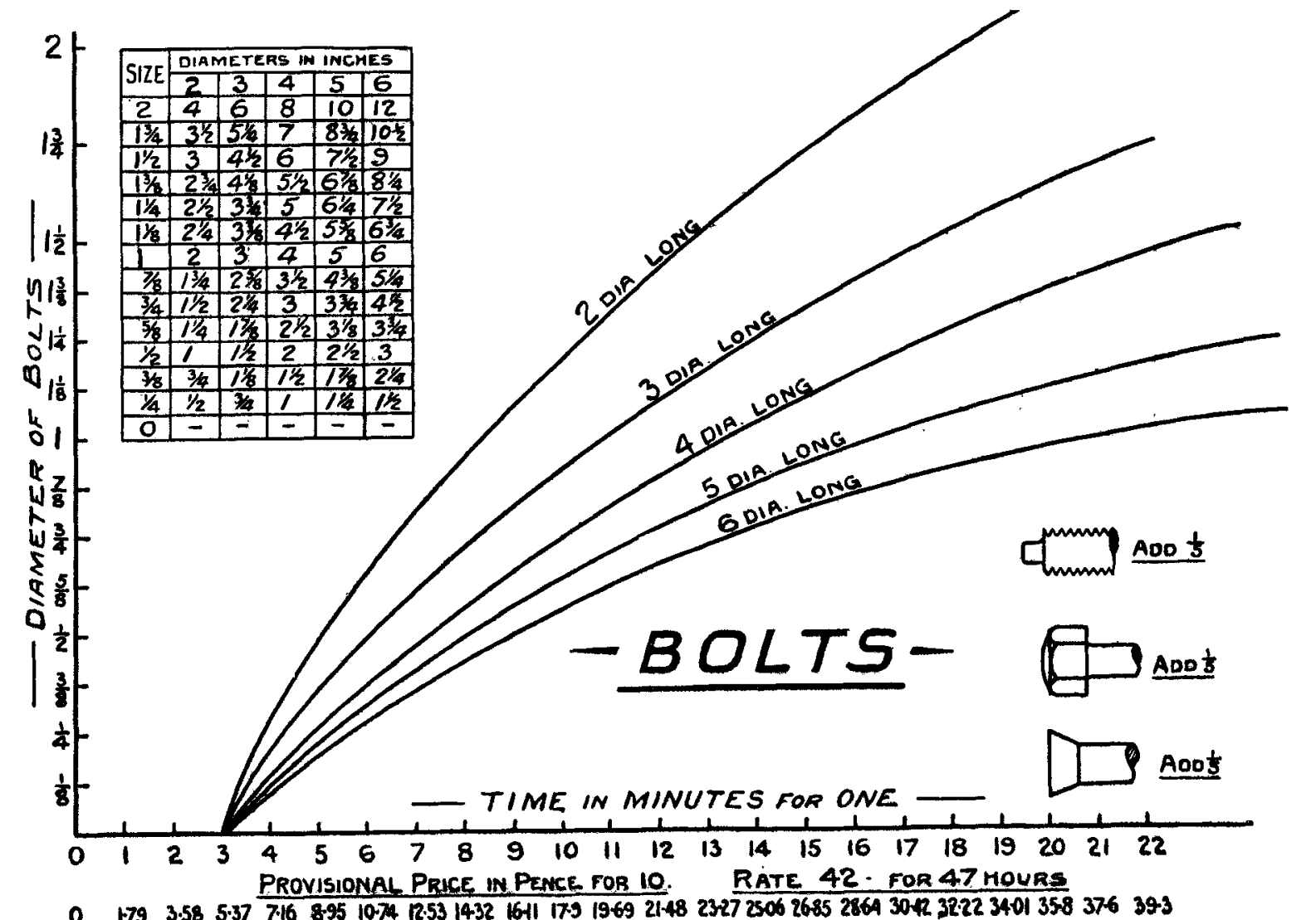




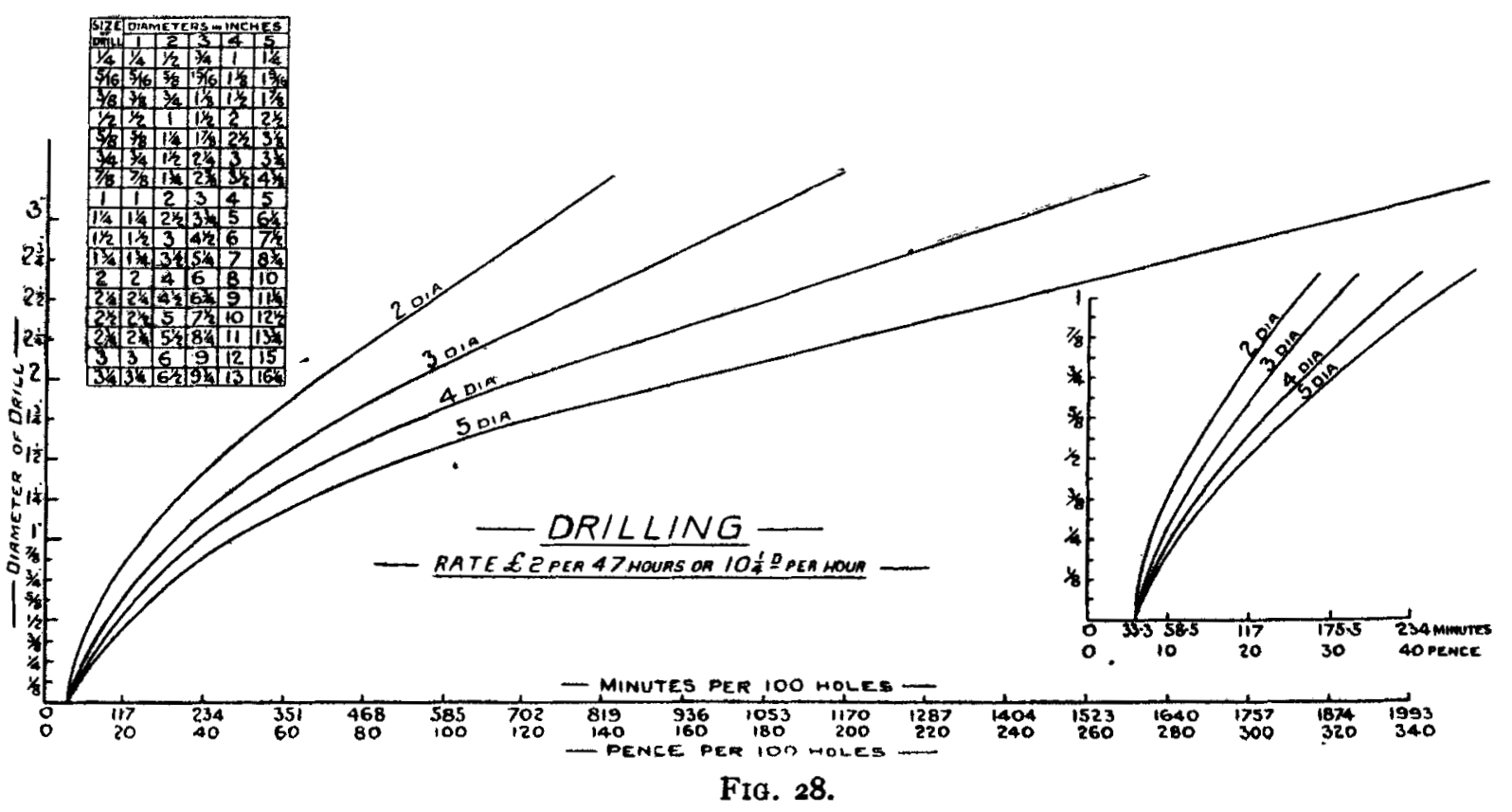




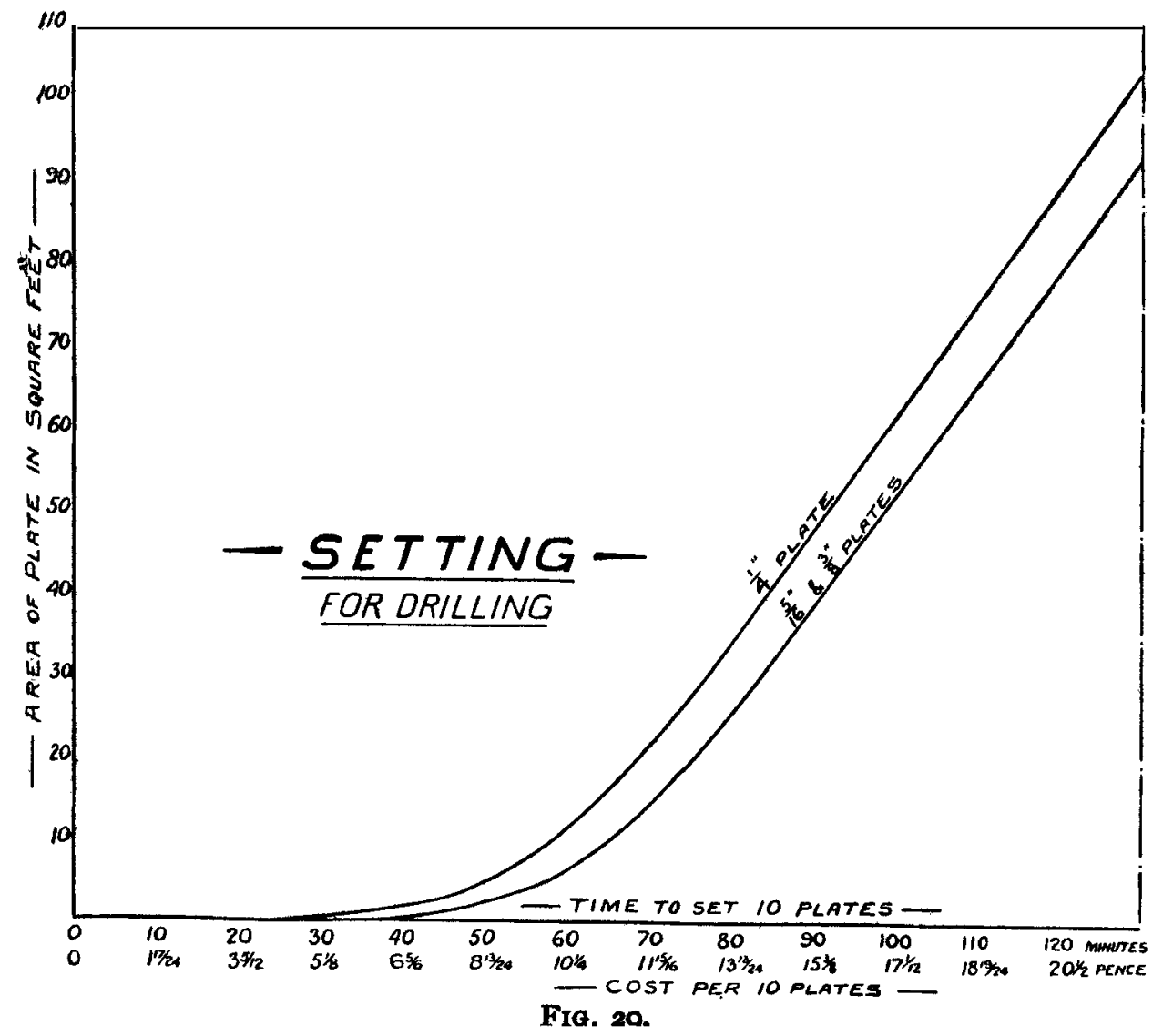

a Fia. 20. 


\section{MACHINE BALANCE 2I8 SHOP (MOTION).}

Assuming machine working life of 5,640 mins., i.e., 5 nights of $9 \mathrm{hrs} .24$ mins. and $5^{\frac{1}{2}}$ days of $8 \frac{1}{2} \mathrm{hrs}$. and piecework estimate based on $33^{\frac{1}{3}}$ per cent. allowance on actual estimated time.

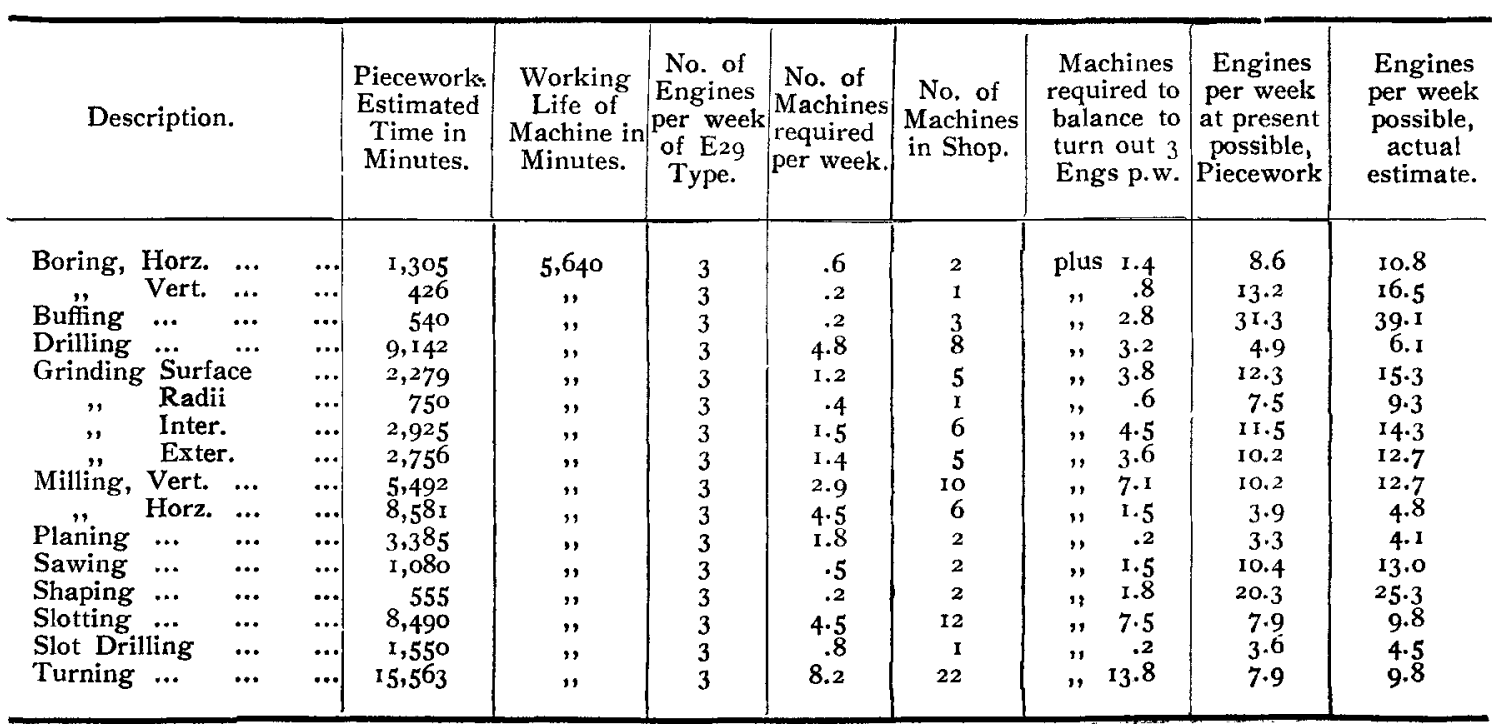

FIG. 30. 


\section{E.29 ORDER.}

218 SHOP (MOTION).

MAN POWER BALANCE.

Based on one week of 47 hrs. and piecework estimate.

\begin{tabular}{|c|c|c|c|c|c|c|c|c|c|c|}
\hline Description. & $\begin{array}{c}\text { No. of } \\
\text { men em- } \\
\text { ployed, } \\
\text { Day and } \\
\text { Night } \\
\text { Shifts. }\end{array}$ & $\begin{array}{c}\text { Rate } \\
\text { per } \\
\text { week } \\
\text { (Basis). }\end{array}$ & $\begin{array}{c}\text { Working } \\
\text { Hours } \\
\text { per week } \\
\text { (Time } \\
\text { and one- } \\
\text { third). }\end{array}$ & $\begin{array}{c}\text { Total No. } \\
\text { of men } \\
\text { employed } \\
\text { (Day and } \\
\text { Night } \\
\text { Shifts). }\end{array}$ & $\begin{array}{l}\text { Total } \\
\text { possible } \\
\text { Hours per } \\
\text { Week. }\end{array}$ & $\begin{array}{c}\text { Piecework } \\
\text { Estimate } \\
\text { (In Hours). }\end{array}$ & $\begin{array}{l}\text { No. of } \\
\text { Engines } \\
\text { per week } \\
\text { possible } \\
\text { (On Time } \\
\text { (Work). }\end{array}$ & $\begin{array}{l}\text { On Piece- } \\
\text { work } \\
\text { (Time } \\
\text { and one- } \\
\text { third). }\end{array}$ & $\begin{array}{l}\text { On Time } \\
\text { and one- } \\
\text { half. }\end{array}$ & $\begin{array}{c}\text { On } \\
\text { Double } \\
\text { Time. }\end{array}$ \\
\hline 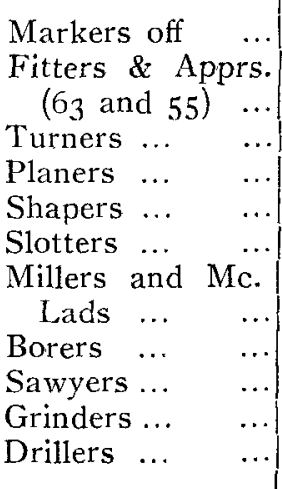 & $\begin{array}{r}7 \\
118 \\
40 \\
3 \\
5 \\
19 \\
49 \\
\\
2 \\
8 \\
30 \\
18\end{array}$ & $\begin{array}{l}49 /- \\
46 /- \\
15 / 6 \\
46 /- \\
42 /- \\
42 /- \\
42 /- \\
42 /- \\
14 / 6 \\
46 /- \\
35 /- \\
39 /- \\
40 /-\end{array}$ & $63 \frac{1}{3}$ & 299 & $18,93^{6 \frac{2}{3}}$ & $1,923^{\frac{1}{2}}$ & $7 \cdot 4$ & $9 \cdot 9$ & II.I & $x 4.8$ \\
\hline
\end{tabular}


SUMMARY OF ENGINE BALANCE (MACHINE SHOP).

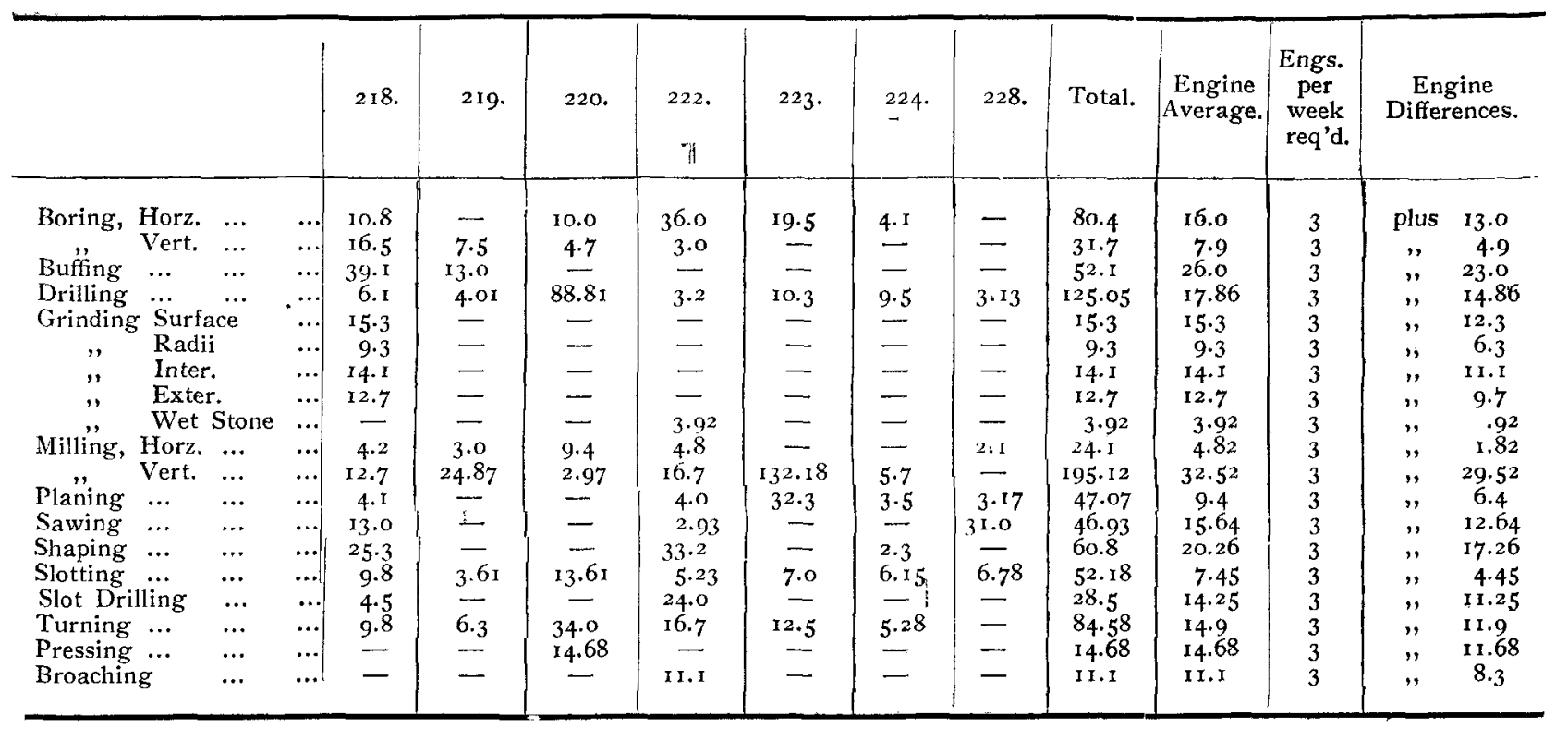

FIG. $3^{2}$. 
SUMMARY OF MAN POWER BALANCE. MACHINE SHOP.

\begin{tabular}{|c|c|c|c|c|c|c|c|c|c|c|}
\hline Graduation. & 218. & 219 & 220. & 222 & 223 & 224 & 228. & Total. & $\begin{array}{c}\text { Engine } \\
\text { Average. }\end{array}$ & Remarks. \\
\hline On time work $\ldots$ & $7 \cdot 4$ & 3.8 & 4.6 & 6.6 & 6.6 & 3.9 & $3 \cdot 75$ & $3^{6.65}$ & 5.2 & \\
\hline $\begin{array}{r}\text { On time and one-third } \\
\text { (piecework) }\end{array}$ & $9 \cdot 9$ & 5.1 & 6.1 & 8.9 & 8.8 & $5 \cdot 3$ & 5.0 & 49.1 & 7.0 & \\
\hline On time and one-half ... & I I . I & $5 \cdot 7$ & 6.9 & 9.9 & 9.9 & 5.8 & 5.6 & $54 \cdot 9$ & $7 \cdot 9$ & \\
\hline On double time... & 14.8 & 7.6 & 9.2 & 13.2 & 13.2 & 7.8 & $7 \cdot 5$ & $73 \cdot 3$ & 10.4 & \\
\hline
\end{tabular}

30 per cent. to be added to above where third shift is worked.

Fia. 33. 
MACHINE OPERATION.

L.M.D. 35

\begin{tabular}{|c|c|c|c|c|c|c|c|c|c|c|c|c|c|c|c|c|c|c|c|}
\hline \multicolumn{4}{|c|}{ Anritcus. } & \multirow{3}{*}{$\begin{array}{ll}\stackrel{8}{8} \\
0\end{array}$} & \multirow{3}{*}{ 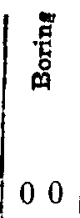 } & \multirow{3}{*}{$\mid \begin{array}{ll}\text { 是 } \\
\text { 量 } \\
0\end{array}$} & \multirow{3}{*}{$\mid \begin{array}{l}\text { 是 } \\
\text { 点 } \\
0 \\
0\end{array}$} & \multirow{3}{*}{ 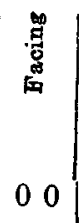 } & \multirow{3}{*}{ 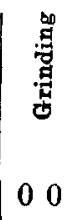 } & \multirow{3}{*}{$\mid \begin{array}{l}\stackrel{80}{3} \\
\text { 昜 } \\
0\end{array}$} & \multirow{3}{*}{ 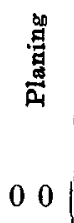 } & \multirow{3}{*}{ 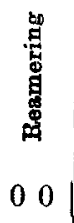 } & \multirow{3}{*}{ 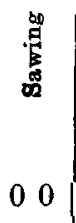 } & \multirow{3}{*}{ 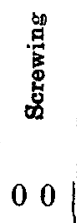 } & \multirow{3}{*}{ 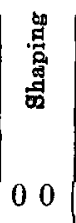 } & \multirow{3}{*}{ 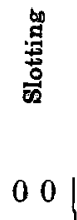 } & \multirow{3}{*}{ 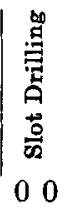 } & \multirow{3}{*}{$\begin{array}{ll}\text { 曷 } \\
\text { 昜 } \\
0 & 0\end{array}$} & \multirow{3}{*}{$\begin{array}{l}\text { Time in } \\
\text { Minutes } \\
0000\end{array}$} \\
\hline rd. & & Machine & & & & & & & & & & & & & & & & & \\
\hline & 00 & & 00 & & & & & & & & & & & & & & & & \\
\hline 1 & 111 & 1111 & 11 & 11 & 11 & 11 & 11 & 11 & 11 & 11 & 11 & 11 & 11 & 11 & 11 & 11 & 11 & 11 & 1111 \\
\hline 2 & 222 & & 22 & 22 & 22 & 22 & 22 & 22 & 22 & 22 & 22 & 22 & 22 & 22 & 22 & 22 & 22 & 22 & \\
\hline 3 & 333 & & 33 & 33 & 33 & 33 & 33 & 33 & 33 & 33 & 33 & 33 & 33 & 33 & 33 & 33 & 33 & 33 & \\
\hline 4 & 444 & & 44 & 44 & 44 & 44 & 44 & 44 & 44 & 44 & 44 & 44 & 44 & 44 & 44 & 44 & 44 & 44 & \\
\hline 5 & 555 & & 55 & 55 & 55 & 55 & 55 & 55 & 55 & 55 & 55 & 55 & 55 & 55 & 55 & 55 & 55 & 55 & \\
\hline 6 & 666 & 6666 & 66 & 66 & 66 & 66 & 66 & 66 & 66 & 66 & 66 & 80 & 66 & 66 & 66 & 66 & 66 & 66 & 6666 \\
\hline 7 & 777 & 7777 & 77 & 77 & 77 & 77 & 77 & 77 & 77 & 77 & 77 & 77 & 77 & 77 & 77 & 77 & 77 & 77 & 7777 \\
\hline 8 & 888 & 8888 & 88 & 88 & 88 & 88 & 88 & 88 & 88 & 88 & 88 & 88 & 88 & & 88 & 88 & 88 & 88 & 8888 \\
\hline 2 & $\begin{array}{lll}9 & 9 & 9 \\
3 & 4 & 5\end{array}$ & $\begin{array}{l}9999 \\
67889\end{array}$ & $\begin{array}{rl}9 & 9 \\
10 & 11\end{array}$ & $\begin{array}{cc}9 & 9 \\
12 & 13\end{array}$ & $\begin{array}{c}99 \\
1415\end{array}$ & $\begin{array}{cc}9 & 9 \\
16 & 17\end{array}$ & $\begin{array}{r}99 \\
1819\end{array}$ & $\begin{array}{rr}9 & 9 \\
20 & 21\end{array}$ & $\begin{array}{r}9 \\
22\end{array}$ & $\begin{array}{l}9 \\
24\end{array}$ & $\begin{array}{l}9 \\
26\end{array}$ & & & & $\begin{array}{ll}9 & 9 \\
34 & 35\end{array}$ & $\begin{array}{c}99 \\
3637\end{array}$ & $\begin{array}{c}9 \\
38\end{array}$ & $\begin{array}{r}9 \\
40\end{array}$ & \\
\hline
\end{tabular}

Fia. 34. 
HAND OPERATION.

L.M.D. 36

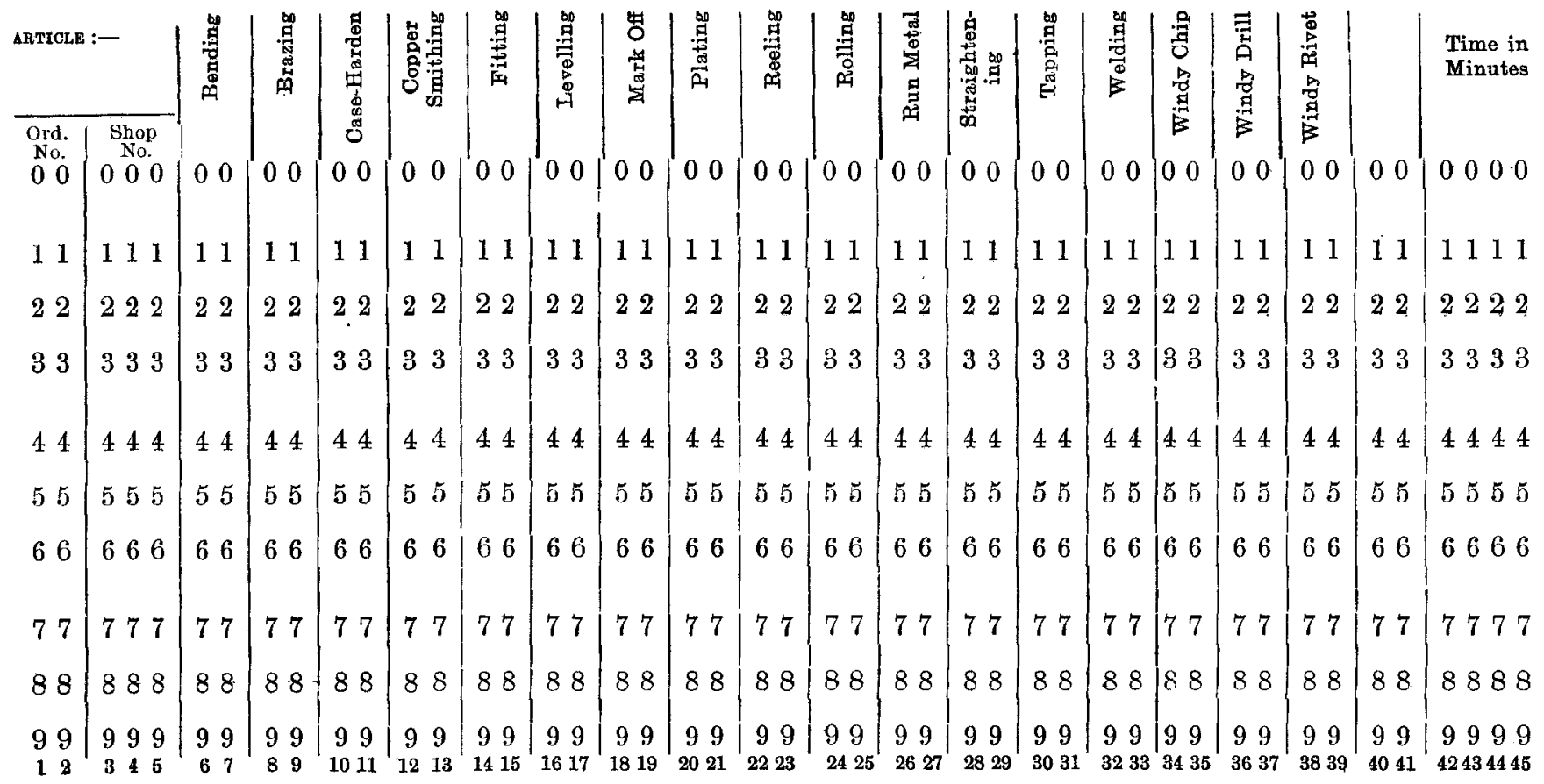

FIG. 35 . 


\section{DISCUSSION.}

The Chairman: We are much indebted to Mr. Howell for coming forward to give us his Paper, but it contains such a mass of information that one is at a loss to know just what to say. The Author covers much ground, and the Paper conveys rather more information than the title led one to expect. In theory Mr. Howell sets out to forecast the cost and the time of production of an engine much in the same way as a railway company does in compiling its time-tables, and says that work must be done strictly in accordance with these time-tables. We all know that in regard to railway time-tables, the trains adhere strictly to the scheduled times, but I should like to ask the Author whether the works adhere as closely to his Paper figures as our railway trains adhere to the company's published figures?

The Author says, in the workshops with which he is connected, the machines have been practically limited to one speed. I presume that this speed has been adjusted within the limits of the capacity of the machine to suit the best wearing qualities of good tool steel. All that remains for the operator to do is to keep the machine in motion. I shall be glad to know whether he has found any difficulty in this respect.

He lays stress on the fact that it is wise to know the cost of a job as soon as it is finished. By this I presume he means he keeps pace with the work production and the cost at the same time. This is very desirable, as it is little use knowing the cost at too late a date, but to do this requires a sufficient and proficient staff, and if I may, I would like to ask Mr. Howell can he give us the number and value of this staff in relation to the number of workmen employed in production.

The Author in his Paper has only dealt with the engine side of a locomotive, and has not taken into account any part of the manufacture of a boiler. The boiler in an ordinary locomotive repair shop is probably the main repair, and from the point of view of repairs is the controlling factor. In the case of new work, with a suitable boiler shop, there is nothing to prevent boilers coming forward in due time to meet the engine part in the erecting shop. The main thing in new work is, as the Author says, to have every part of the shop balanced, so that every part required for the completion of a locomotive arrives in the assembly shop at the time required. 
Mr. E. Colclough (Cambrian Rlys., Oswestry): The Paper is most interesting, and there are one or two points which have cropped up which I should like to mention.

In the first place it looks to me rather a serious item to take the works manager away and create another one by introducing a production engineer. It appears to me that, in the first place, a works manager's duty is absolutely and essentially that he should control the whole business and work of the works which are put into his charge. I should like to know if this production engineer is under the works manager, and does he submit his views and decisions to the works manager for his final consent?

Generally speaking, I should say that the principles on which this system have been laid down are based on premium bonus; the Author would find a little more difficulty on straight piecework when arriving at accurate times and costs.

Again, I think that the Paper treats really on a shop actually manufacturing, and not manufacturing and repairing at the same time. A difficulty would crop up very soon if the Author had both systems going in the same works. If we could have had some figures which would have helped us in repairs in general, it would have been a very great help to some of us. Chopping and changing, and pulling out of one machine and putting something else in, is a very constant occurrence. The mean speeds and feeds generally adopted is done for mass or quantity production, but generally, in a small shop, I think it is more advisable to take each machine on its own basis, especially in an old works where a few new machines are introduced amongst a lot of old ones. The only real way, and saving way, is to take a machine on its own feed and speed.

Then, again, there is another difficulty; the whole thing is based on the production office working out these basis prices. These prices are submitted to the foreman, and that foreman is an intermediary between the firm and the men. How would he go on if, as I have just lately experienced, the men objected absolutely to an intermediary, and wanted a clear deal between the firm and themselves?

The question cropped up in this way. We had taken the feeds and speeds of all tools in the shops. We had worked out the whole of our jobs. and given the basis times in which each of these jobs should be done, and generally speaking, they could be worked to; but great objection was made that the whole thing must be agreed on between the foreman and the men. As soon as ever they got to know that the thing 
had been worked out on feeds and speeds, the men were up in arms in a minute.

I am glad that our Chairman mentioned the boiler shop, because in some cases on piecework in the boiler shop probably there are eight or nine men on one job, and at the same time, and probably these eight or nine men are on different rates, and it is a very difficult matter to give a real straightforward piecework price for any job under these conditions. It is quite easy, I know, generally speaking, if every man is paid the same rate, and they are working on similar machines as in a machine shop.

I should like to know actually the number of men engaged in this production office work in proportion to the men in the shops.

Mr. E. N. R. Hurt (L. \& N.W. Rly., Horwich) : I should like to know if the Author's firm has any centre to get work passing through the departments to schedule time, or is the working so perfect that it is possible to get it through under schedule time, i.e., giving a day or days in hand? Have they any system for seeing that work does get through as quickly as possible, and again, is there any incentive to the foreman or supervisor of a department to gain time over the official time-table?

The Author: In reply to the Chairman, although the works adhere very closely to the Paper figures and times, we would not say that they are so good as railway trains. Regarding the machine speeds, we had a little trouble at first owing to the operators being very dubious as to whether or not the price would be cut if they made too much money, but after consultation with the trades union officials and a guarantee signed by the directors that once the piecework price had been fixed it would not be altered unless the means or methods of production were changed, the men soon got over their distrust, and laid themselves out to earn as much money as possible.

With regard to the number and value of the staff in relation to the number of workmen employed in production, roughly the whole production department costs $\mathrm{i} \frac{3}{4}$ per cent. of the total on-cost. I regret that I cannot give fuller details in a public meeting, but this figure itself should be sufficient to show the value of the application of the system.

Regarding not taking any cognisance of the boiler side of the locomotive, as our boiler shop is away in another section of the works, and did not happen at the time to 
come under the control of our section of the works, I, as production engineer, on the one side, did not bother with the other side, but it is worked on precisely the same lines.

Replying to $\mathrm{Mr}$. Colclough's remarks, the production engineer is under the works manager and really acts as assistant works manager. The principles upon which the system is laid down are not those of premium bonus, but are straight piecework. The Paper treats upon a shop actually manufacturing and not repairing, but the system could be applied to repair work fairly easily. Regarding the foreman being the intermediary between the firm and the men, in our case the trades union asked for this, but it would be far easier for the production office engineer (rate fixer) to deal directly with the men. It the system is properly explained to the men, and the men have practical proof that they can earn more money with the assistance of the production department, the thing will soon work very smoothly.

Where there are several men on the same job having different rates, it is usual to base the piecework price on the average rate, because a man getting the higher rate will be getting that rate because he is an exceptionally good workman, while the man getting the lower rate will probably be new to the job, and what one gains by his superior skill, the other will be compensated by the bigger allowance made to the man who is not so skilful.

With reference to Mr. Hurt's remarks, we have a finished work store where any surplus material above the programme and not required in the erecting shop is retained, and we work to a time-table similar to that on the railway, each shop having a definite time for the delivery of its unit assemblies. To see that the work gets through as quickly as possible a chaser takes charge of an order, and any work lying about the shops not in operation is queried, and not allowed to rest if no satisfactory reason can be given. The incentive to the foreman or supervisor of a department to gain time on the official time-table lies in the fact that all the staff are paid a very substantial output bonus and a nominal salary, and the curve of the output bonus rises very sharply so that, say, the 3 2nd engine in a month is worth more in bonus than the first ten. 